\title{
Reform of Secondary Education in Post-Communist Estonia: Advancing or Dismantling Social Cohesion
}

Cassandra Jo Garcia

West Virginia University

Follow this and additional works at: https://researchrepository.wvu.edu/etd

\section{Recommended Citation}

Garcia, Cassandra Jo, "Reform of Secondary Education in Post-Communist Estonia: Advancing or Dismantling Social Cohesion" (2011). Graduate Theses, Dissertations, and Problem Reports. 728. https://researchrepository.wvu.edu/etd/728

This Thesis is protected by copyright and/or related rights. It has been brought to you by the The Research Repository @ WVU with permission from the rights-holder(s). You are free to use this Thesis in any way that is permitted by the copyright and related rights legislation that applies to your use. For other uses you must obtain permission from the rights-holder(s) directly, unless additional rights are indicated by a Creative Commons license in the record and/ or on the work itself. This Thesis has been accepted for inclusion in WVU Graduate Theses, Dissertations, and Problem Reports collection by an authorized administrator of The Research Repository @ WVU. For more information, please contact researchrepository@mail.wvu.edu. 
Reform of Secondary Education in Post-Communist Estonia:

Advancing or Dismantling Social Cohesion

Cassandra Jo Garcia

Thesis submitted to the College of Arts and Sciences at West Virginia University in partial fulfillment of the requirements

for the degree of

Master of Arts

in

History

\author{
Robert Blobaum, Ph.D., Chair \\ Joseph Hodge, Ph.D. \\ Elizabeth Fones-Wolf, Ph.D. \\ Department of History
}

Morgantown, West Virginia

2011

Keywords: Estonia; Post-Communism; Education Reform; Language Immersion; Integration 


\section{ABSTRACT \\ Reform of Secondary Education in Post-Communist Estonia: Advancing or Dismantling Social Cohesion}

Cassandra J. Garcia

The concept of integration in the most basic of senses refers to intermixing of groups of people that were previously segregated. Estonia, as the focal point of this study as opposed to another post-Soviet nation, is unique in that it is such a small country, and this state possesses a variety of traits that distinguishes it from other states in the process of reform and from other multicultural states. Over $25 \%$ of the population of Estonia speaks Russian as their mother tongue, and currently the youth of these Russian-speaking communities are feeling the weight of the integration process. Education reform has been put in place in Russian-language schools so that the students will speak Estonian better and therefore will have more opportunities than previous generations to become well integrated in society. This seems harmless, but a debate has arisen over the period of this reform's implementation that questions the potential success of this integration.

This thesis focuses on the implementation of the Estonian integration program, specifically through the educational reform and whether or not the measures enacted have been successful. By looking at the process of the education reform in two phases, visiting specific Russian-language and Estonian immersion schools, interviewing individuals integral to the process itself and cross-referencing this study with others done on similar topics in the past, the researcher is able to analyze the results of the Estonian integration program as it stands in 2011. Using models of multiculturalism and its critiques, the researcher brings a better understanding of the diversity of the country.

One of the largest setbacks for this country and its attempts at reform is the uneven distribution of resources, be they qualified teachers, materials, textbooks, monetary funding or otherwise. With any integration, there are debates, and among the main reasons for success or failure of such integration programs, the researcher outlines that community involvement and a positive environment, as well as realistic expectations are all solid contributors. 


\section{TABLE OF CONTENTS}

Table of

Contents.......................................................................................ii

Table of

Figures.......................................................................................iv

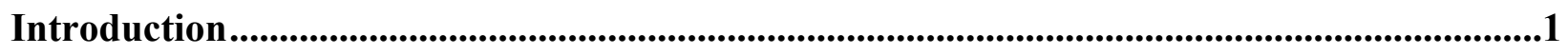

Chapter 1: Integration Strategies and Policies .................................................................................13

Chapter 2: Theory-Multiculturalism and Critiques .............................................................20

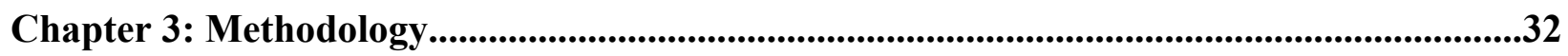

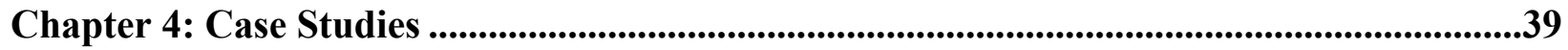

Chapter 5: Interviews..................................................................50

Chapter 6: Analysis................................................................55

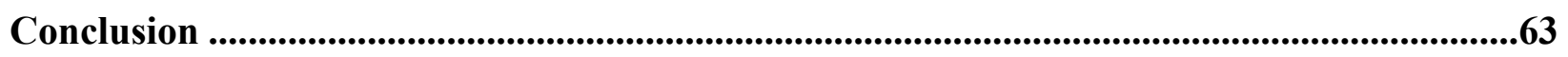

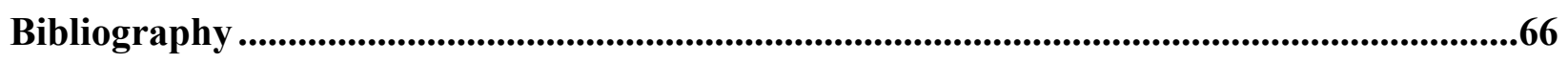

Appendix A

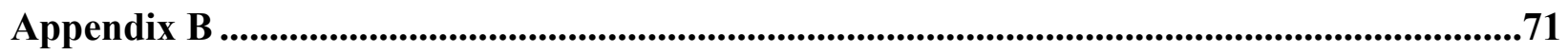

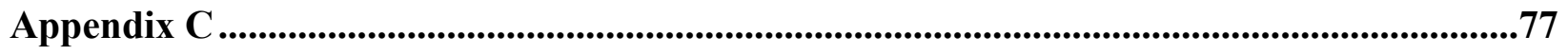

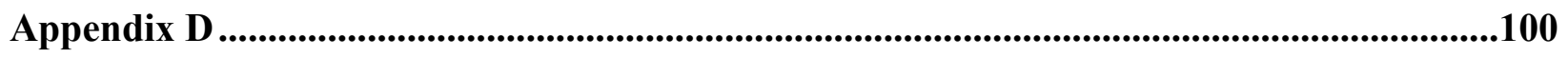

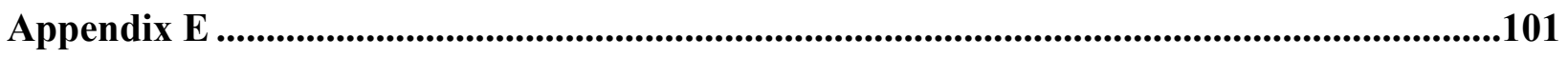

Appendix F......................................................................................104

Appendix G..............................................................................106 


\section{TABLE OF FIGURES}

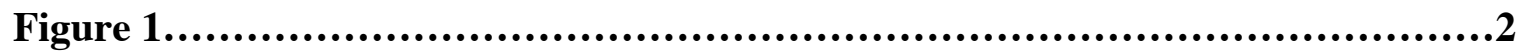

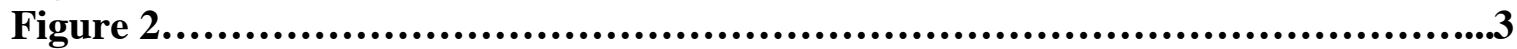

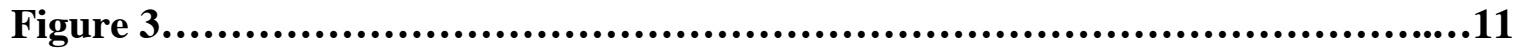

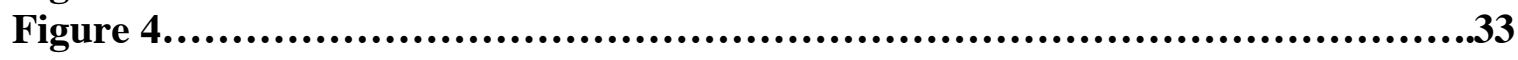

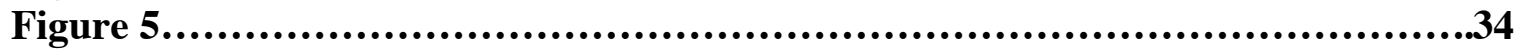

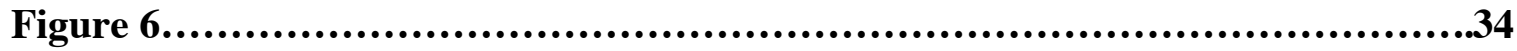

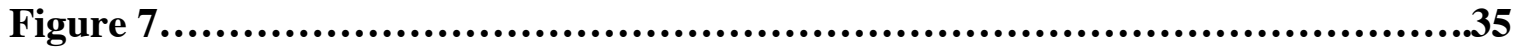

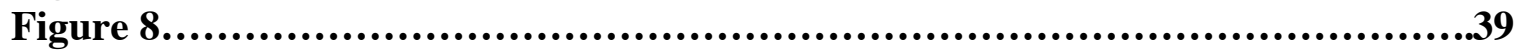

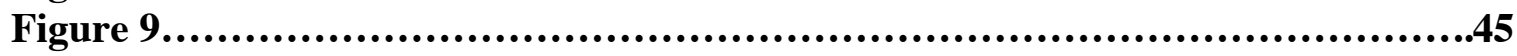

Figure 10..............................................................................48

Figure 11...............................................................................61

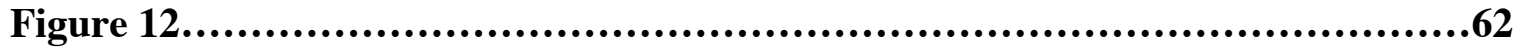




\section{INTRODUCTION}

\section{General Overview of Educational Reform in Estonia}

Every society needs change. Whether by electing new officials, revising antiquated statutes, or technological advancements, change is a fact of life and governance that no person or society can escape, democratic or otherwise. In recent history, "reform" is a word that has become synonymous with Post-Soviet/Post-Communist countries in the years since the fall of the Berlin Wall. Political and economic reform have been some of the most debated and publicized aspects of international relations and history, as these topics not only effect the countries being reformed, but have global consequence. Another type of reform has also had a great deal of impact on these transitioning countries, despite the fact that it has generated far less interest on the global scale. Educational reform is one of the ways that post-Soviet countries are struggling to overcome their communist pasts and provide their future leaders with more resources than they have had in previous years so that these countries can grow and prosper as new independent democratic states.

That this is not as popular a discussion topic as economic or political reform is not evidence of transition without controversy. One of the unique qualities of post-Soviet states is the diverse ethnic demographics due to the Soviet Union's policies on ethnicity and governmentsanctioned migrations across the USSR, which encouraged the dispersal of ethnic groups. ${ }^{1}$ However, since transitioning to independence and the reinstatement of official national languages outside of the Russian Federation there seems to be a problem creating an educational policy that provides for non-titular language speakers, namely the Russian-speaking minority. Because the break with the Soviet Union in these countries was generally motivated by strong nationalist movements, it would logically follow that the political goals and policies brought forth by the new states favored this nationalist approach. Perhaps this doesn't happen

\footnotetext{
${ }^{1}$ For more information on the ethnic mobilization in the Soviet Union, refer to Philip G. Roeder "Soviet Federal and Ethnic Mobilization," World Politics (Jan. 1991): 196-232.
} 
consciously, but the effects that the Soviet-era politics and policies had on today's reformers are evident in the types of changes they have been making.

One country that stands out among the other post-Soviet states in its progress in educational reform since it regained its independence in 1991 is Estonia. Unlike other countries that broke from the Soviet Union around the same time, Estonia did not choose to give the Russian language equal status as an official language with Estonian. Despite the large minority within the small country that speaks Russian as a mother tongue, the Estonian language alone holds this privileged position. Problems arose over the legal rights of the Russian-speaking population, as citizenship in Estonia requires the ability to speak Estonian. The following map ${ }^{2}$ shows the immigrant population's knowledge of the Estonian language by county as of 2008:

\section{Immigrantrahvastiku eesti keele oskus maakonna järgi, 2008}

Knowledge of the Estonian language of immigrant population by county, 2008

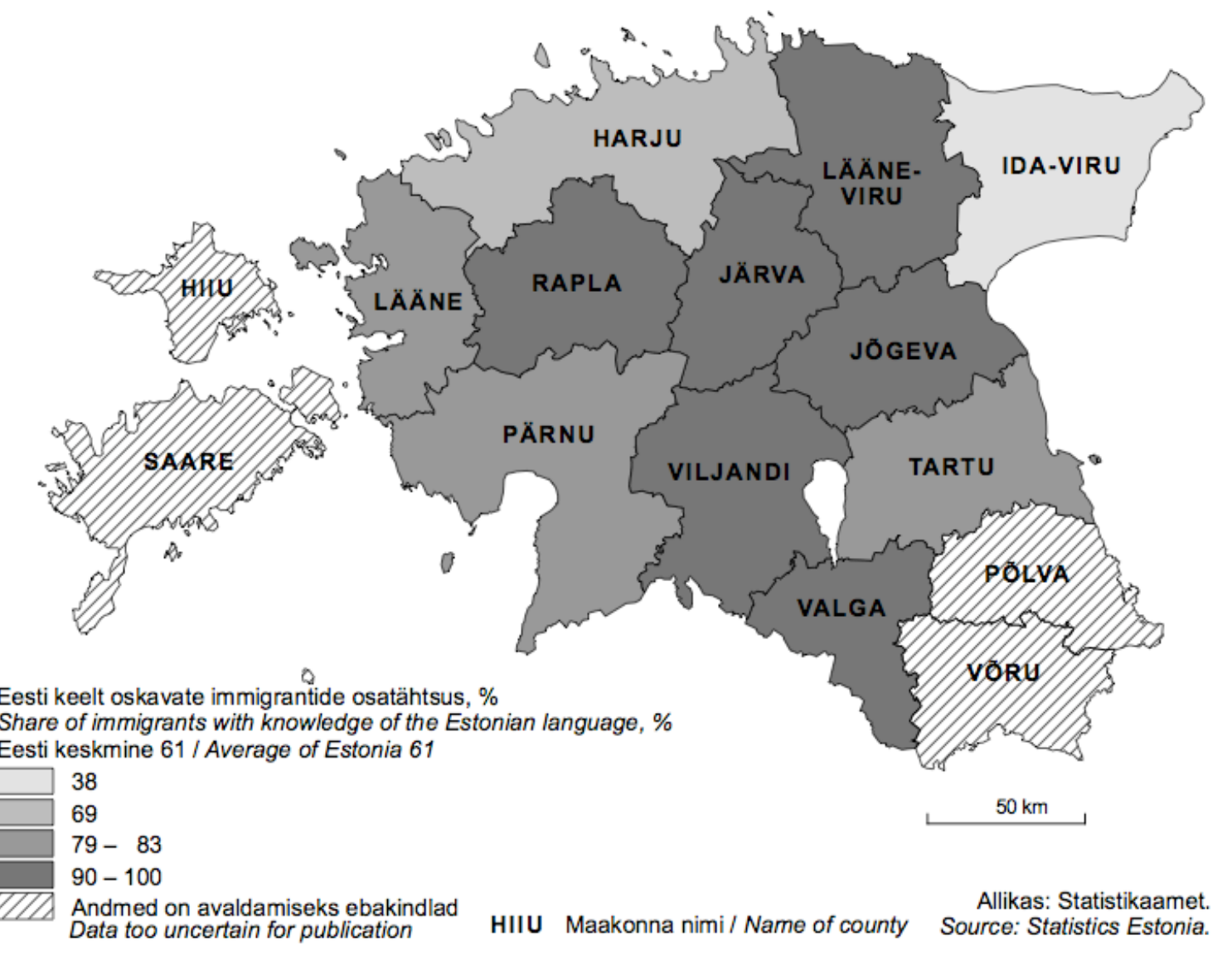

\footnotetext{
${ }^{2}$ Map taken from Siim Krusell, "Data and General Characterization of Immigrant Population," Immigrant Population (2009): 10.
} 
Figure 1

This map tells us little about the issues surrounding the immigrant population, who are mostly Russian-speakers, because it does not offer any context within which this data can be interpreted. To get a better understanding, juxtaposition is needed with a different map ${ }^{3}$ showing the dispersion of the immigrant population across the country.

Immigrantrahvastiku osatähtsus maakonna järgi, 2008
Share of immigrant population by county, 2008

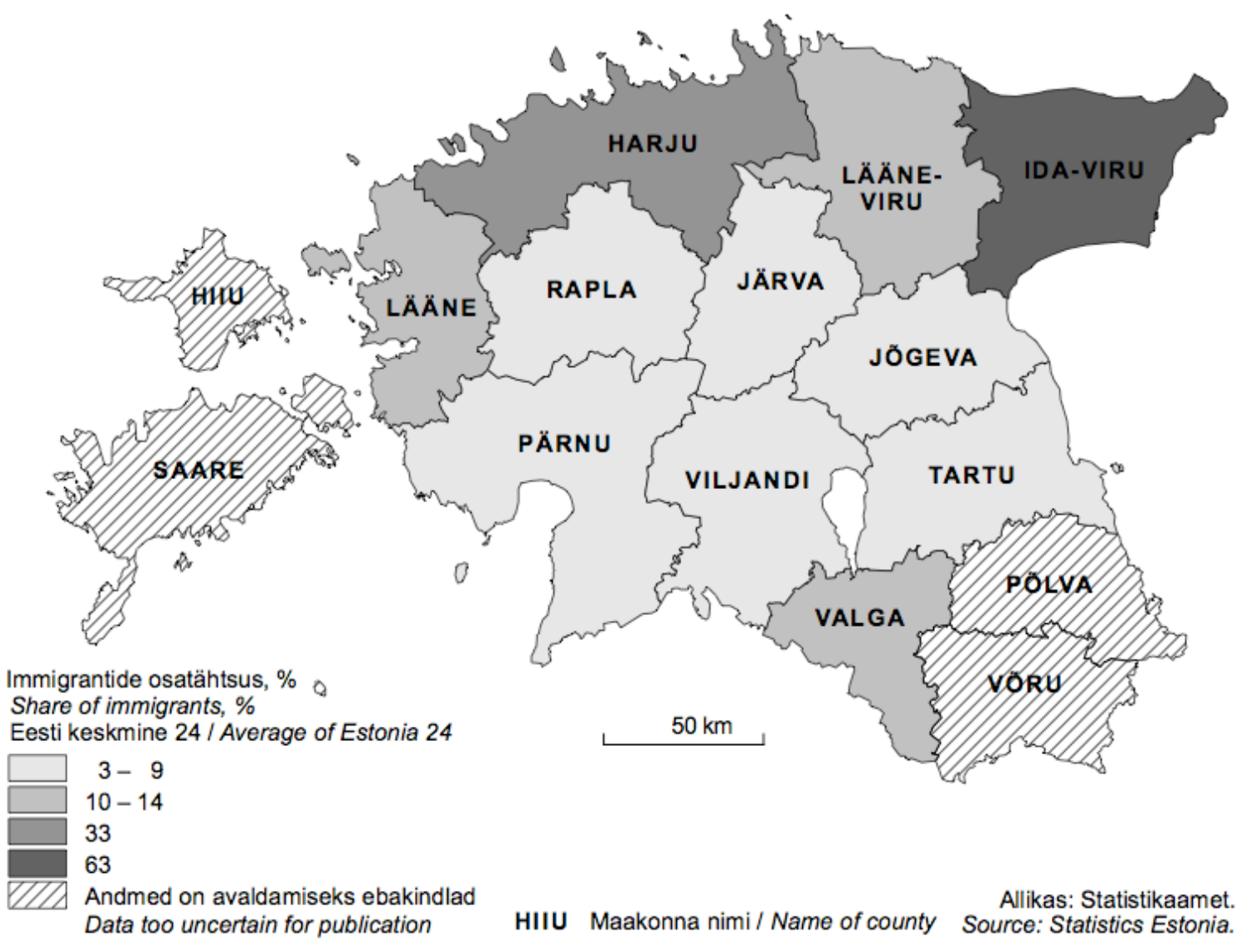

Figure 2

From the second map we can see that the majority of the immigrant population resides in either Harju County, where the capital city of Tallinn is located, or in Ida-Viru County, where

${ }^{3}$ Krusell: 10. 
one can find the border with the Russian Federation in the city of Narva. From the first map we can see that these same two counties are the areas where the immigrant populations have the second lowest and lowest knowledge of Estonian language, respectively. This poses a significant problem to the Estonian society. There exist two separate and strong communities, the Estonian-speaking and the Russian-speaking, within the borders of one country. Communication and cultural barriers exist between the two, sometimes causing a marginalization of the Russian-speaking population. Without citizenship, they have no right to vote in the country they live, despite having been born there in some cases. Russian-speaking communities are strong in the sense that they can be autonomous in certain regions. For years, these communities took it upon themselves to maintain their cultural heritage through Russian language-of-instruction schools where there were enough students to constitute a school. The disparities between the communities are very evident: economically, occupationally, and educationally, the Russian-speaking communities have been and continue to be disadvantaged.

The Estonian government chose to take action through reform. Specifically for the purposes of this paper, the reform that will be discussed is educational. One method of educational reform that reflects the issues that surround the collapse of the Soviet Union and the democracies that were born, or re-born out of that collapse, is that of integration. Often, integration is a term used for the process aiming to deepen the involvement of an immigrant or minority population in the broader society. This process is not exclusive to post-Soviet countries, as it can be seen in Canada, Spain, Belgium, and elsewhere. Implementation of the integration schemes can be very difficult even in a well-established democracy such as Canada. ${ }^{4}$ Given the added historical element of post-Soviet countries and the issues and attitudes that go along with this, the implementation of an integration policy, especially one that is governmentmandated, can cause turmoil in the domestic population as well as initiating interest on the global level.

\section{Historical Overview}

\footnotetext{
${ }^{4}$ Adel Safty, "French Immersion and the Making of a Bilingual Society: A Critical Review and Discussion," Canadian Journal of Education,13, 2 (Spring 1988): 243-262.
} 
The history of the territory now known as Estonia has been extremely dramatic, especially in the last one hundred and fifty years. As the saying goes, "History is written by the victors," it would seem that the current protagonists of the Estonian state, the Estonians, are wielding the pen. But there are also at least two sides to every story, and while these are highly subjective in nature, it would be beneficial to understand how these stories differ and how they are the same.

Historical events that are typically emphasized by the Estonian mindset are far more contemporary, whereas history in the eyes of a Russian might stretch much further back into the territory's past. An example of this might be the time period during which Estonia was included in the Russian empire. Estonia's history includes multiple foreign rulers: the Swedes, the Germans, and the Russians. Under the Russian tsar, the feudal system was still intact, and as a result, Estonian agrarians still lived under the rule of Baltic German barons or Russian nobility. Their rights grew as Imperialist Russia progressed, and eventually in 1905 the people of Estonia, as well as the other Baltic States for that matter, took the chance to initiate self-rule. Unfortunately, this attempt at independence failed, but later when the Tsar was preoccupied with fighting internally and externally thanks to the Bolsheviks and the appearance of the First World War, Estonia declared independence in 1918. Like the other independent nation-states popping up all over the European continent, this was a very proud moment for Estonia. Konstantin Pats, the prime minister, instituted a democracy, but soon the government would be more of a dictatorship in practice. This would last 20 years until the Second World War would interrupt, and the Soviets would invade and occupy the territory, thanks mostly to the non-aggression pact signed with Nazi Germany without any consideration for the independent Estonian Republic. ${ }^{5}$ The achievements that had been gained from independence, such as education, literature, music in the national language of Estonian were now subjected to the commands of the communist leadership of the USSR.

The Estonian Soviet Socialist Republic was created, and the authoritarian regime of the Soviet Union practically controlled its every move. For most Estonians, this is a dark time. Some Estonians were able to prosper in this setting, but there were also persecutions of people

5 Toivo Raun, Estonia and the Estonians (2002): 264-265. 
who held different political ideologies than those who were in power. One of the events of this time period that had the most impact on the society was the mass deportation of the Estonian intelligentsia, political rivals to the state, and generally anyone who the state deemed undesirable on June $14^{\text {th }}, 1941 .^{6}$ The Second World War continued around them, and Nazi Germany also occupied Estonia for a spell. There was a seemingly passive resistance to this new power in the region, which occasionally was associated with the Red Army, but as was the case in all other Nazi-occupied countries there were also Estonians who collaborated with their occupiers either voluntarily or by force. ${ }^{7}$ In 1944, the Nazis retreated from their defeat and the Soviet Union returned to occupy the area. Later, in an attempt to fight "bourgeous nationalism," the policies of the USSR allowed for large groups of Russian, Belorussian, Ukrainian, and many other migrants to come to Estonia for work and who eventually settled, one of the causes of the current ethnically diverse atmosphere (citation). More deportations were ordered during the reign of Stalin, and the greatest of these happened on March $26^{\text {th }}, 1949$, over 20,000 Estonians were sent to Siberia. ${ }^{8}$

The Soviet Union's control over the policies of Estonia extended to the educational system. Fifty years ago, the students of the University of Tartu were only allowed to reference books that had been approved by officials of the Estonian SSR or the Soviet Union. Bilingual education was forced upon the Estonian population, while the Russian-speaking population was not required to learn or speak Estonian. A new period of "Russification" came again in 1978, teaching Russian in the kindergartens, increasing the amount of Russian language classes at the higher levels, and increasingly trying to promote the use of Russian language in Estonia. ${ }^{9}$ The language policies of the USSR were strictly enforced. And until two years after the restoration of the independent Estonian state, Soviet troops were still a major part of this enforcement.

In 1991, the August Putsch gave Estonians a cue to restore their own independence. When the change took place, it was as if a wealth of culture flooded back---literature, folk music, etc. With the re-birth of Estonian nationalism came encouragement within the population and

\footnotetext{
${ }^{6}$ Olaf Merlesmann and Aigi Rahi-Tamm, "Soviet Mass Violence in Estonia Revisited.” Journal of Genocide Research (2009) :308.

${ }^{7}$ Ibid, 308 .

${ }^{8}$ Ibid, 308.
} 
from the government to actively participate in events and study that had formerly been restricted by the Soviet Union. Such freedom was not taken lightly, and soon the government enacted policies in order to ensure the future of the state, and by proxy, the culture of the Estonian people. According to the Russian population, however, these policies were implemented quite suddenly, and gave little time for adaptation.

Estonia has taken steps in the reformation of the educational system since its regained independence. This study will concentrate on the policies and data from case studies that help to elucidate this issue. However, it should be taken into consideration that there are certain aspects of the problem that cannot be regulated or monitored by the government. In this thesis, some of the factors that will be focused upon are history, geography, demography, and environment. These aspects are not always able to be changed by the government, but more often is the case they are changed by time, by communities, and by discourse. This creates a problem, as such policy changes given a relatively short time for implementation, can be hard to analyze and quantify.

A decade might not seem long enough, especially when the school children, the "guinea pigs" of the first language immersion programs instituted in Estonia, haven't even matriculated yet, let alone attempted to enter university or the job market. The real life results are yet to be seen. Lastly, it should be understood that language is too dynamic of a factor to fit into either the "unchangeable factor" or the "reform-able" categories that have already been established. In the context of integration, a common language spoken across the two communities decreases the communication barrier, of course, but language acquisition in the strictest sense does not imply willingness to integrate into society or loyalty to the state, for that matter. The language laws that correspond with citizenship, as well as the expansion of job opportunities that comes with bilingualism could also be causes for an increase in Estonian-language knowledge among the Russian-speaking population, and the immigrant population on the whole. With these ideas in mind, is more possible to analyze the actions that have been taken by the Estonian government and more specifically by the Estonian Ministry of Education and Research, and also provide a

${ }^{9}$ Romuald Misinuas and Rein Taagepera, The Baltic States: Years of Dependence, 1940-1990. (1993) :195-196. 
context within which to credit or critique those actions while taking into account the limitations that they face.

Domestically, one factor that seems impossible to change that faces the Estonian government in its efforts to reform and integrate the society is the ethnic distribution of the population. As seen in the maps from previous pages, the Russian-speaking communities are predominantly urban-dwellers and also populate a large majority of the northeastern region. This has the potential to cause problems in many forms-policy implementation in the official language, lack of qualified Estonian-speaking teachers in certain areas, etc.

Estonia, as the focal point of this study as opposed to another post-Soviet nation, is unique in that it is such a small country, and this state possesses a variety of traits that distinguishes it from other states in the process of reform and from other multicultural states. For example, the geopolitical location of Estonia makes it a particularly interesting research focus. As a member of the European Union and as a neighbor of the Russian Federation, the government of Estonia is under scrutiny from both Brussels and Moscow. It is when the opinions of these two major players differ that pressure can be placed on this small state. Both entities have a genuine interest in the issues that are presented by the large Russian-speaking minority population. The European Union has expressed concern in the past for the rights of the Russian-speaking population, mostly in regards to citizenship and education. Currently a major influence on Estonian policy-making, the EU supports Estonia's efforts to further integrate the Russian-speaking population into the broader Estonian society. This falls in line with the same goals of the European Union, creating a pan-European identity in a multicultural environment.

The Russian Federation does not support the reforms made by the Estonian government to the educational system. The large eastern neighbor, sometimes seen as the greatest threat to the Estonian nation, takes the human rights approach to this situation. People born in the Estonian SSR, the same territory as today's Republic of Estonia, are denied citizenship based on language requirements. By narrowing the qualifications for citizenship status in such a way, the Estonian government has disenfranchised Russian-speaking inhabitants of Estonia. Citing loyalty to the persons living in Estonia who share a common language and culture, the leadership of the Russian Federation has actively petitioned on behalf of the Russian-speaking population of 
Estonia. However, Estonians may see Russia's critique of the reforms as trying to increase its sphere of influence, something to be frowned upon in the post-Soviet era. With Estonia's ties to the rest of the European Union and access to the Baltic Sea, it is in the Russian Federation's best interests to maintain positive relations with Estonia and its citizens, especially in the economic and industrial spheres.

In the grand scheme of things, the number of factors that the Estonian Ministry of Education and Research or the Estonian government in general has any control over is fairly limited. The focus has been mostly on the national curriculum, ${ }^{10}$ and how to unite the different schools and programs beneath one umbrella of core courses that must be taught in some shape or form at every school across the country. Another key point that can be included in the reformable factors is qualified teachers. ${ }^{11}$ In some places, schools inherited teachers from the Soviet era who were not properly qualified to teach in the new democratic context. The Integration Foundation, a part of the Ministry of Education and Research, was able to initiate a way of monitoring the progress of integration, from teaching standards and adherence to curriculum changes to the students' performance. ${ }^{12}$ It is hard to say whether the things being monitored were promoting social cohesion like the government had planned or if they were simply producing the statistics that are required with no actual social interaction between ethnicities. This is to say that requirements instituted by the government should not necessarily be interpreted as progress towards integration, but means toward an end. A more accurate gauge of social cohesion would be the willing involvement of not just Russian-speaking Estonians in integration and language

${ }^{10}$ Sobhi Tawil (ed.), "Curriculum Change and Social Inclusion: Perspectives from the Baltic and Scandinavian Countries," Final Report of the Regional Seminar held in Vilnius, Lithuania, (December 5-8, 2001): 71-79.

${ }^{11}$ Gabrielle Hogan-Brun, "Language in education across the Baltic: Policies, Practices and Challenges," Comparative Education, $43-4$ (2007): 564.

12 "Integration in Estonian Society: Monitoring 2000" (Tallinn, Institute of International and Social Studies and Integration Foundation); "Integration in Estonian Society: Monitoring 2002" (Tallinn, Institute of International and Social Studies and Integration Foundation); "Integration in Estonian Society: Monitoring 2005" (Tallinn, Institute of International and Social Studies and Integration Foundation); "Integration of Estonian Society: Monitoring 2008" (Tallinn, Institute of International and Social Studies and Integration Foundation). These reports have compiled various articles dealing with subjects relating to or critiquing the implementation of the Estonian Integration Strategies. Occasionally, specific articles from these reports are also cited individually throughout this study. 
immersion programs, but the society as a whole's increased voluntary involvement in the integration process - through extracurricular activities, exchange programs, immersion schools, volunteering, monetary donations, etc.

The most substantial obstacle that the Estonian government faces in its attempt to create a comprehensive system of education that is accessible to all people within the state and which will promote the idea of social cohesion beyond the walls of the school building is linguistics. Figure 3 gives a visual representation of the statistical data from the 2000 Estonian Census on Language Use. ${ }^{13}$ The primary language used in Estonia is notably the official language. Looking at the current situation in the educational system where the students are separated according to maternal language, it is quite evident that Estonian policies are not motivated by extreme nationalism. However, this does not mean that developments in Estonia are not of significant interest to the Baltic region, the European Union and on a global level.

Those who are not ethnically Estonian, such as the ethnically Russian as well as Belarusian, Ukrainian, Swedish, German and Jewish minorities, are given the opportunity through the Law on Cultural Autonomy for National Minorities to go to schools for their education, where the nationally-mandated curriculum is taught in their native tongue. This law was established in 1925 by the first Estonian nation-state, which gained independence in 1918 like many others in Eastern Europe at the close of the First World War. Through the developments of integration programs instituted by the Estonian government, the Estonian language will become a more prominent focus in schools where the language of instruction is not Estonian, which in most cases is Russian. Therefore, the crux of the situation is obviously language, and it seeps into the realm of "reform-able" and "unchangeable" in many respects.

${ }^{13}$ Data gathered from http://www.vm.ee/?q=en/node/5689. (March 29, 2011--last accessed.) 


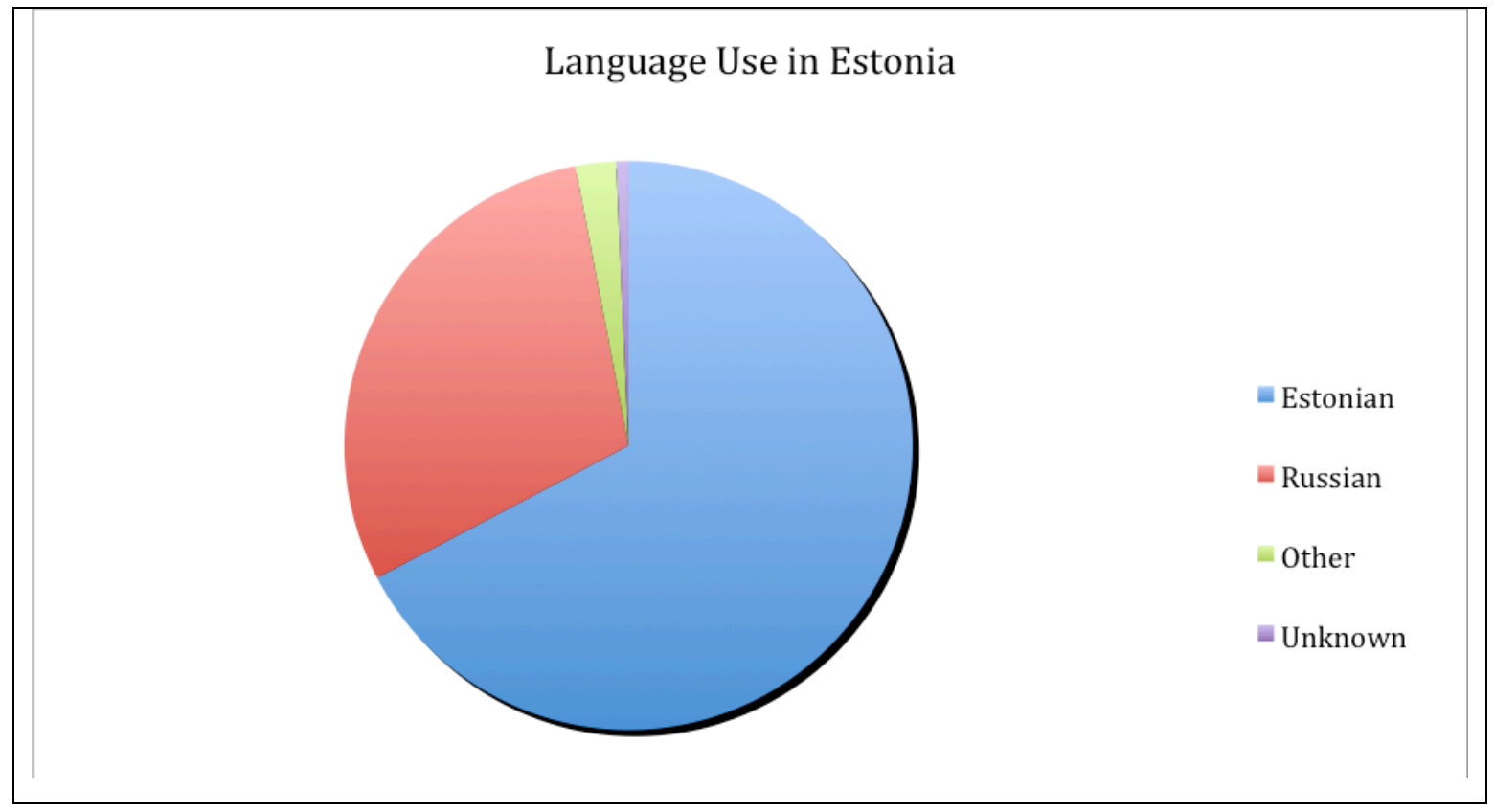

Figure 3

This begs us to question if reform is the solution. Perhaps intense regulation of schools, from the curriculum to the teachers, and to the teaching methods used in classrooms, will actually bring about the change that the government and the society want and expect or, maybe the problems will resolve themselves with time. Or what if the reforms somehow manage to reinforce the communication and cultural barriers present in Estonian society? Debates have been swirling around the idea of education for centuries.

This thesis will focus on the question of Estonian education reform of the past two decades. Is the Integration Program designed by the Estonian government, more specifically the emphasis placed on the education reform, actually progressing Estonian toward social cohesion, and how? Expectations will differ across regions and across ethnicities. Perceptions of success or failure of certain programs, teachers, or protocols can have a large impact on their actual success or failure, as well as the success or failure of programs, teachers or protocols in the future. The main hypothesis of this thesis is that the relative success of the initial stages, from 2000-2007, of integration programs, such as immersion classes, could potentially be overshadowed by the relative stagnation of the second phase, from 2007-2013. This thesis poses that a variety of factors contribute to the success or failure of education reform. Among the most important of these factors, community involvement and expectations are foreseen as being the most influential 
on the students and the teachers, which are the means of measuring a successful or failed program. This thesis also suggests that strong community involvement is the key to a successful educational program - the community has the most influence on the environment, whether it is positive, negative, or indifferent. For these programs to achieve the success that they wish to in building a cohesive society in Estonia, the concepts of community involvement and expectations need to be addressed.

This thesis is devoted to understanding the process of minority integration in Estonia and attempts to contextualize the issue in the frameworks provided by theorists and critics of multiculturalism. In the ever-globalizing world, the opportunity to dissect the issues of a country or a people can provide an example for other countries with similar issues. By using educational reform as a lens by which to view the integration process, the enormous scope that the concept of integration entails can be narrowed, allowing for a more focused analysis. The first chapter details the policies and implementation of the integration program for schools in Estonia. After this general background is given, Chapter Two provides a theoretical framework that will be constructed based upon the ideas of multiculturalism and its critique through a review of previous academic literature. In Chapter Three, the methodology of the research employed in this thesis as well as its limitations will be examined. In Chapter Four, the case studies of three distinct schools where the successes and failures of the integration program in Estonia can be seen are given. Chapter Five attempts to identify the different perspectives and expectations that this particular integration program has created through the interviews and data gathered from other sources. Chapter Six seeks to synthesize Chapters Four and Five so that a analysis can be given. Conclusions will be made drawn from the analysis and suggestions will be made on how best to resolve the problems that still face the reformation of the Estonian educational system. 


\section{CHAPTER ONE: Integration Strategies and}

\section{Policies}

The concept of integration in the most basic of senses refers to intermixing of groups of people that were previously segregated. This can happen in any arena, with people of any ethnicity, for any purpose. In the case of this study, the above definition is very similar to if not the same as the goal of the Estonian government in its implementation of various reforms in order to create a more cohesive society. The intentions seem harmless, and in fact, beneficial to all involved, but the element that is missing from this restructuring is process by which it happens. The attempt is established to de-marginalize the Russophone portion of the population, and this occurs in many ways, but the most prominently discussed is the need for more Estonian language to be taught in Russian-language schools.

The government of Estonia has taken numerous actions in regards to forming a more cohesive society through integration since the fall of the Soviet Union. Strategies were developed by experts in fields relating to social inclusion, employment, politics, the economy, and education as to how best to create environments where the society would be encouraged to progress towards a cohesive unit. The first phase of the Estonian State Integration Program was initiated in 2000 and was in progress until 2007, with the intention of providing a framework for integration to guide all governmental institutions. In their own words, this program is necessary because,

As a result of the extensive migration that took place during the Soviet period, a community using Russian as its first language has developed in Estonia, and many of its members lack a sufficient outlet to the rest of society. Linguistic attributes also largely determine the places these people work and live, the education they receive and their social mobility. Sociological investigations undertaken from the mid-1990s suggest the formation of a "two societies in one country" model in Estonia, which may become dangerous both socially and from the point of view of security policy. It is particularly disturbing that many nonEstonian adolescents fail to find sufficient opportunities for self-realisation. ${ }^{14}$

14 “Integration in Estonian Society 2000-2007” (March 14, 2000): 13. 
The program proposed changes in three specific areas: linguistic-communitive integration, legal-political integration, and socio-economical integration. As far as educational reform is concerned, the government created a sub-program focusing on education included in the "linguistic-communicative" section. ${ }^{15}$ The aims of this were to increase Estonian language and civics education in state schools and to monitor the teachers of Russian-language schools and adherence to Estonian-language standards in the classroom. ${ }^{16}$ Nation-wide legislation was enacted to enforce the obligatory study of Estonian as a second language in all non-Estonian medium schools. ${ }^{17}$ Immediately, the number of Estonian courses offered at schools across Estonia increased dramatically. Another portion of this legislation in correlation with education reform focuses on the teachers and teacher training. The requirements for language have been set at the medium- and high-proficiency levels for teachers and school administrators, respectively. ${ }^{18}$ The Common European Framework of Reference for Languages: Learning, Teaching, Assessment, most known as CEFR, would qualify these levels as B1 or B2 for "medium" and C1 or C2 for "high," on the scale from A1-C2. ${ }^{19}$ The program outlines the need for various teacher-training programs for both Estonian-language acquisition and also for teachers' training for specific subjects in Estonian. Other aspects of the education reform touched upon in the program's guidelines are provision of adequate teaching material and cooperation between Estonian- and Russian-medium schools. ${ }^{20}$ Overall, the plan set in place in 2000 for educational reform in Estonia appears to be quite comprehensive.

A second phase was proposed for 2008-2013, where more changes are proposed again for a higher level of integration for the ethnic minorities of Estonia (namely the Russian-speaking population), with more focus this time on employment and social integration. The newer program has more funding both internally and externally, and therefore the expectations are decidedly higher. For one, the goals for the second phase of the Integration Strategy are much more fine-tuned. It is evident from the language and focus of the latest program that the

\footnotetext{
15 Ibid., 22.

16 Ibid., 24.

17 Ibid., 26.

18 Ibid., 26.

${ }^{19}$ CEFR - “Common European Framework of Reference (for Languages)," Council of Europe, Www.coe.int.

20 "Integration in Estonian Society," 25-27.
} 
government agencies have tried to improve on some of the less effective legislation of the first phase, such as the changing of some terminology — what was "linguistic-communicative integration" in the first program is referred to in the newer program as "educational and cultural integration." This shows that the persons who constructed the second program recognize the broader problems that can occur in the educational setting, and not limiting the program to initiating reform only to the linguistic aspect of the problem. ${ }^{21}$ Acknowledging the potential oversights made by the first program, the plan for 2008-2013 states,

"On the one hand, cohesive functioning of the society calls for a common educational system, which in Estonia requires that all members of society know the Estonian language. In addition, conditions that allow other ethnic groups to preserve their culture and language need to be improved in Estonia. Support for inter-cultural communication, which is one of the components of achieving the sense of social security, will be continued, recognizing every person's right to partake in the culture of one's mother tongue. Attention will still be given to teaching Estonian and education in general, but above all EIS places importance on activities outside the formal education system, which helps establish and maintain good relationships between people of different linguistic backgrounds. It is important to achieve the understanding in the society that cultural differences in the society are actually a resource and not a problem. Expanding the shared Estonian and Russian-language information field is also planned for this area as part of cultural integration." 22

Along with the abstract changes to terminology in this outline of the most recent program, there are also practical changes that will be implemented over the course of the 5-year period. One particular change will be the "transition to Estonian language of instruction as part of the general education system strategy is set by the Basic Schools and Upper Secondary Schools Act. ${ }^{23}$ In other words, schools will start to teach certain subjects in Estonian as opposed to the maternal language, gradually increasing the number of subjects being taught in Estonian until 2011 when they will constitute $60 \%$ of the curriculum. ${ }^{24}$

These new policies initiated by the Estonian government are decidedly ambiguous and may prove difficult to realize not because the intentions are unclear or not well thought out. In fact,

21 "Estonian Integration Strategy, 2008-2013," 15.

${ }^{22}$ Ibid., 19 .

${ }^{23}$ Ibid., 28.

${ }^{24}$ Ibid., 28. 
the opposite is true. These policies are supposed to be implemented countrywide, and as stated previously, the regions are not evenly matched. In this sense, the policies have to be set at the lowest common denominator. For the purposes of this thesis, three different counties, specifically Harju County, Ida-Viru County and Tartu County, will be used to demonstrate these inequalities later in the chapter titled "Case Studies." One reason they were chosen is because these three counties make up the majority of the population of Estonia. Another reason is that they have very different resources available to them. Demographically, each has different proportions of Estonian- and Russian-speaking populations.

So as not to inadvertently penalize the regions or specific schools that were ready for a more challenging step toward integration, the Integration and Migration Foundation: Our People, ${ }^{25}$ established a language immersion program. This would give funding and support to schools that have met certain criteria to implement language immersion classrooms in their schools. This started in 2000 with four schools and five classes (one school had two classes). Over the years this program has developed into a prestigious collection of 34 schools, 34 kindergartens and almost 4000 pupils. The Integration Foundation has its own Strategic Plan for the Language Immersion Program for 2009-2013.

MISA included 5 priorities in its strategic plan. They were:

1. Immersion is a widely instituted, high quality CLIL program. ${ }^{26}$

2. An Immersion program quality assurance system is being implemented.

3. Stakeholders systematically cooperate to support immersion program expansion, contributing resources to its management, development, and implementation.

4. Favorable conditions are in place to support the professional development of teachers.

5. The learning environments support student and teacher development.

These priorities differ from the strategic goals of the governmental integration strategies,

${ }^{25}$ Referred to hereafter interchangeably as "MISA" or "Integration Foundation." 
and yet they are still based upon the principles of the integration process. The Integration Foundation created this plan in cooperation with the partnering schools, and as the product of collaboration, the ideals it stresses in these goals and their sub-goals is mutual support, motivation, and continual growth. ${ }^{27}$

In the current situation, Russian-speaking students differ from the other minorities of Estonia in a variety of ways. Seeming to be the least integrated into society, the ethnically Russian population of Estonia makes up almost a fourth of the overall population in a relatively small country. There are cities in Estonia where the majority of the population speaks Russian; in fact, in the capital city of Tallinn, fifty percent of the population is Russian-speaking. At the very least these numbers cause communication problems with the Estonian majority, and at times this has led to tense inter-ethnic debates ${ }^{28}$ on government policies and even physical violence, such as during the Bronze Soldier incident in 2007. Considering the tumultuous history that the two nationalities have shared in the $20^{\text {th }}$ and $21^{\text {st }}$ centuries, it is necessary to be sensitive in presenting the different perspectives contributing to this issue.

The government of Estonia has taken many steps to be proactive in creating opportunities for ethnic integration and promoting a more pluralistic society. Activities and campaigns to fulfill the objectives of the strategic integration programs have been initiated and funded by the government and other external organizations. ${ }^{29}$ Therefore, it is puzzling to see statistical data showing little progress toward the end goal of social cohesion and to listen to individuals from the Russian-speaking community saying that they still don't feel accepted into Estonian society. ${ }^{30}$ Most articles that focus on Estonian educational reform revolve around the

${ }^{26}$ CLIL-Content and Language Integrated Learning

${ }^{27}$ An interview was conducted with three members of the Integration Foundation, the full text of which can be found in Appendix B.

${ }^{28}$ Such as the forced implementation of $60 \%$ of the curriculum of grades 9-12 done in Estonian language, Russian as a second official language, citizenship laws based on Estonian language acquisition, etc.

29 This subject will be touched on further in the chapter on Integration. For more information, please reference the evaluation done by TNS Emor, "Phare Project 2003-2004, Estonian language in training and teaching in Estonian for non-Estonian speakers"(Dec 2005) and the Integration Foundation's "Tallinn Conference on Conceptualizing Integration (Oct 18-19, 2007)"

${ }^{30}$ This can be found in the collection of individual interviews in Appendix C. 
human rights argument that a segregated school system, like the one in Estonia, would most likely not give equal opportunities to the students.

This is logical, as the predecessors of such systems, for example in the United States during the segregation of the African Americans and White Americans, were founded on the principle "separate but equal," which later was declared unconstitutional and unjust because it obstructed equality. Integration programs have been implemented in many countries in the past; Canada is a particularly influential country because it is also one of the ones now helping the Estonian nation with the organizational tactics and funding. In an effort to establish a solid unified country made up of many nationalities and two languages, Canadians implemented a French-immersion so that students could experience and appreciate the culture and language of the French-speaking Canadians as well as of the English-speaking. This was quite beneficial in helping children learn French, but as for the issue of whether or not this has aided the establishment of a unified society is still debated. Geographically speaking, the Francophone communities are still mainly based in Quebec, and although there is more equality, there is not much intermixing of the groups. By using Canada as its example, is Estonia setting itself up for the same fate?

The steps being taken toward integrating Estonian society have been in place for a decade, and the society still seems to be fragmented. The students with Russian as their native tongue are statistically improving ${ }^{31}$ in their Estonian language skills, but contact between the national groups is still sporadic and stereotyping is still a prevalent in inter-ethnic attitudes. ${ }^{32}$ In my opinion, there seems to be tension below the surface of educational reform, which can be seen in the Estonian and Russian-media portrayals of the integration process, statistics regarding the immigrant population and the integration monitoring, as well as from other recent studies and

${ }^{31}$ The statistics show an average improvement in Estonian language leaving exam scores over the past few years. Upon more specific study, it should be noted that the statistics showed greater improvement in some schools and while other schools failed to meet even the previous years' scores, with a high correlation to their region. This will be discussed later in the thesis in more detail.

${ }^{32}$ Kulliki Korts, "Inter-Ethnic Attitudes and Contacts between Ethnic Groups in Estonia," Journal of Baltic Studies, 40-1 (2009): 121-137. 
my own personal interviews with individuals from Estonia (both Russian-speaking and Estonianspeaking). 


\section{CHAPTER TWO: Theory}

In this chapter, the theoretical foundations of Estonia's education reform are presented, terms and concepts essential to the issue are properly defined, literature with related subject matter is reviewed, and an overview of the research methodology is given, providing a general structure within which this study can be understood. By first presenting John Berry's approach of intercultural strategies, specifically acculturation, a necessary groundwork is laid for the forthcoming analysis. Additionally, three different theorists of multiculturalism are identified for their relevance to this issue and whose conceptual frameworks will also be used to shape my analysis. With many of the terms and related concepts having multiple interpretations, this chapter will focus on the more crucial phrases and words, defining them in the way they should be understood in the context of this paper. This will be followed by an in-depth literature review of other academic articles and studies pertaining to this field, so as to give a broader understanding of the scholarship to which I hope to contribute. And finally this chapter will expand on the specific reasoning behind the research and the methods employed in attaining the data.

\section{Theories}

It is important to address the fundamental issue that lies at the basis of the education reform process in Estonia, which is to say the cultural and linguistic differences present in the society. The Russo-phone population is the largest minority in Estonia, and since the collapse of the Soviet Union, it, along with the ethnically Estonian majority, has been dealing with the numerous problems that arise during the transition to democracy in a pluralistic society. One of these problems is in the development of a public education system that is beneficial to all parties involved. Linguistically and culturally this has proven to be difficult, but the government and the population have implemented new policies to resolve the issues and create a more cohesive society.

To rely solely on one theory to explain the inner workings of a complex system of educational integration would at best be shortsighted. By primarily using Berry's approach to 
acculturation to analyze of the current situation in Estonia, this paper will be able to explain the reception of such policies in the Russo-phone communities, assess the expectations of policies implemented by the government, and generally critique the applicability of multiculturalism in this scenario. To be sure, acculturation and multiculturalism are not mutually exclusive, however, in examining these two concepts, the former is more applicable in its definition to the situation in Estonia. However, in order to achieve the goals of this paper, the role of multiculturalism must be addressed; therefore, the theories of John Rex, Will Kymlicka and James Banks will be introduced as a comparison and a supplement to Berry’s model.

\section{Berry's Approach to Acculturation}

Berry's idea of intercultural strategies "refers to the various ways that groups and individuals seek to acculturate and relate to each other as they carry out their lives when living in a society with two or more cultures." 33 One of the ways that Berry outlines in his article, "Immigration, Acculturation, Adaptation" as mentioned in the title, is acculturation. ${ }^{34} \mathrm{He}$ explains his use of the word acculturation as the changes in cultural patterns that occur when two or more groups of individuals having culturally different backgrounds interact on a continual and first-hand basis. In other words, this is the process by which a society moves toward social cohesion. Berry recognizes that in practice, the majority of the changes tend to occur in one group, and not in both, although in principle, the term acculturation is inherently neutral. Historically, acculturation is associated with one culture having great power over another, such as the Native Americans in the United States, or the Aboriginals in Australia both assimilating to the English society. It is clear from this that there would be a fear of losing one's cultural heritage, which is strange that the Estonians might not acknowledge this in the Russophone community because Estonians themselves have experienced this type of forced assimilation this century during the Soviet era.

For the purposes of this thesis, the term acculturation is more applicable to the current situation in Estonia regarding educational policies. A culture is made up of many elements, one

\footnotetext{
33 John W. Berry, Juri Kruusvall, Raivo Vetik, "The Strategies of Inter-Ethnic Adaptation of Estonian Russians." Studies of Transition States and Societies 1(1 Nov. 2009): 5.
} 
of which is language. The majority of the Russo-phone population of Estonia identifies with Russian culture and therefore Russian language, ${ }^{35}$ but the only official language of Estonia is Estonian. Knowledge of Estonian language is required for citizenship and participation in the political arena. And although this is understandable when considering the nation's history with the a large neighbor to the East, Estonia's educational reforms should not be classified as multicultural in nature, if the term acculturation is more accurate.

Berry identifies four acculturation strategies:

a) Assimilation-individuals do not wish to maintain their cultural identity and seek daily interaction with other cultures.

b) Separation - individuals place a value on holding onto their original culture and at the same time wish to avoid interaction with others.

c) Integration-individuals hold an interest in both maintaining their own culture and interacting with other groups.

d) Marginalization - individuals hold little interest in maintaining their own culture or having relations with other groups.

From the perspective of the non-dominant group, in this case the Russo-phones in Estonia, the strategy of integration is the most preferable, however, this is not exactly the way that the Estonian government has gone about implementing the current integration program. Next, Berry outlines preconditions in this article that focus on the attitudes and behaviors necessary for a multicultural society aiming at integration to function properly. ${ }^{36}$ These preconditions have set the formula for the methodology, which will be used to create a framework for analyzing the data for this thesis. They are:

a) the widespread acceptance of the value to a society of cultural diversity (i.e. the presence of a positive "multicultural ideology");

34 John Berry, "Immigration, Acculturation, Adaptation," Applied Psychology: An International Review, 46, 1, (1997): 5-68.

${ }^{35}$ Eva-Maria Asari, "Attitudes Toward Integration in Estonia," Immigration Population in Estonia (2009): 25. Table 22 can be found in Appendix C.

${ }^{36}$ Berry, 11. 
b) relatively low levels of prejudice (i.e. minimal ethnocentrism, racism, and discrimination);

c) positive mutual attitudes among cultural groups (i.e. no specific intergroup hatreds);

d) a sense of attachment to, or identification with, the larger society by all groups. ${ }^{37}$

Meeting these preconditions requires effort from both the dominant cultural group, the Estonians, as well as effort from the non-dominant group, the Russo-phones. With this analysis, it will be possible to pinpoint the areas in which the larger Estonian society needs to improve in order for the integration programs to function. As the concepts of social cohesion and integration are still to be realized in many places, research into the reasoning for the potential shortcomings of the program is valid and essentially promotes the success of the program, even if it is still in its infantry or adolescence.

\section{Multiculturalism}

Depending on the ethnic variations and cultural differences existing in a state, the idea of multiculturalism can mean different things. To demonstrate, this thesis will use examples from three of the leading theorists on multiculturalism, John Rex, James Banks and Will Kymlicka, all of whom are cited as secondary sources in the literature review.

In his article, "Multiculturalism and Political Integration in the Modern Nation-State," John Rex lays out the framework of general multiculturalism theory. ${ }^{38}$ Rex uses an example from the United Kingdom, quoting Roy Jenkins in his explanation that multiculturalism is "not a flattening process of uniformity, but cultural diversity coupled with equal opportunity in an atmosphere of mutual tolerance." 39 This is the underlying theme in all literature about multicultural theory. Three particular phrases are stressed in this explanation: "cultural diversity," "equal opportunity," and "mutual tolerance." In this sense, first we are made aware that multiculturalism, as the etymology implies, must include more than one cultural group.

${ }^{37}$ Berry, 11. and R. Kalin \& J.W. Berry, "Ethnic and Civic Self-Identity in Canada," Canadian Ethnic Studies.

38 John Rex, "Multiculturalism and Political Integration in the Modern Nation-state," Revista $H M i C, 3$ (2005) :249-261.

${ }^{39}$ Rex, 252. 
Second, that despite the proportional complexities of the demography, no one group should have an advantage or bias, therefore freeing the multicultural community from discrimination based upon culture. And thirdly, that for everything to work in this community, all parties involved must share a mutual open-mindedness of the others involved, perhaps not anything more than a generalized acceptance, but also nothing less. Rex notes himself that his theories on multiculturalism are not practically applicable to all parts of the world, but that they simply serve as a general framework for multicultural analysis.

He goes on to provide his thesis of "Two Domains"-one that is private, where differences are celebrated, and one that is public, where people are unified under common goals and purposes. It is when the theory delves into the idea of multicultural educational systems that problems begin to arise. Rex notes, "The one institution which clearly straddles both the private and the public spheres is that of the educational system." ${ }^{40}$ As far as general theories go, Rex makes valid points and rationalizes his arguments well, and applies them to various situations in Eastern Europe, where language is a key factor in the establishment of a multicultural society.

James A. Banks and Cherry A. McGee Banks are American theorists who apply the ideas of multiculturalism to the United States educational system in the post-integration era. This concept of multiculturalism focuses on how to reform a mainstream-centric curriculum. Banks and McGee Banks describe how a mainstream-centric education does not only harm minorities whose histories and cultures are being marginalized, but also harms the students from the mainstream culture by "reinforcing a false sense of superiority" and limiting their "perspective and frames of reference," thus harming their ability to think critically. ${ }^{41}$ The duo makes multiple proposals on how to ameliorate this issue in the classroom, specifically in a multiethnic classroom. Unfortunately, this is solely for monolingual classrooms and educational systems going through reform. The theory can be applied loosely to Estonian classrooms, suggesting the integration of aspects of Russian culture into the mainstream classrooms. Particularly, this might be effective in smaller towns where Russo-phone children have already adapted linguistically. However, the broader society cannot yet apply Banks and McGee Banks' theory to the

\footnotetext{
${ }^{40}$ Rex, 253.

${ }^{41}$ James A. Banks and Cherry A. McGee Banks, Multicultural Education: Issues and Perspectives (2001, $3^{\text {rd }}$ ed.): 229.
} 
educational reform in Estonia. This is because of the additional linguistic complexity that is inherent in the integration of Estonia. Banks and McGee Banks focused their research mainly on racial and cultural difference, and the policy changes that they suggest are not as easily adaptable in the context of the Estonian education reform of recent years.

Will Kymlicka has gone the farthest in applying the concepts of multiculturalism to the area and historical situation of Eastern Europe. One of main features of Kymlicka's theory is how minority rights can be viewed in the framework of multiculturalism. In his article "The New Debates on Minority Rights" he deflates the idea of an "ethnically neutral" model of multiculturalism in favor of a nation-building model. In this model the terms "national minority" and "immigrants" are brought up as two distinct sub-cultural groups within a society, which potentially can and should proclaim their minority rights in the nation-building model that Kymlicka proposes. The difficult distinction lies in how the Russo-phones of Estonia should be classified in this theory. If it is understood that a Russian sub-culture has been present in the territory of Estonia for centuries, due to the area's inclusion in the Russian empire and even before, then perhaps the Russo-phones are national minorities and should be given autonomous rule over their educational system. How many generations of immigrants do there need to be until they receive national minority status? Obviously, they are expected to integrate into the larger society, but alongside the programs for integration there is a fear of losing a rich cultural heritage. Due to different perspectives, this is a complicated classification, and really has less to do with educational issues than with minority rights.

These concepts and theories on multiculturalism have proved useful in understanding the benefits that can be gained from an integrated and culturally diverse society. However, all theories tend to lose a bit of substance in their implementation. It is therefore clear that John W. Berry delivers the most applicable theory to the Estonian model. This explains some of the reasons why the transfer of multicultural theory into practice does not always go as planned, because all multicultural situations are very different, and Berry provides a more suitable alternative in acculturation strategies, in general and specifically to Estonia. 


\section{Definitions}

This section is intended to clarify certain words (presented in italics) that could be confusing or have multiple meanings. By defining these terms and presenting a clear meaning to be used throughout the remainder of this study, the explanations of the programs and their goals, the analysis of the case studies, the analysis of the interviews, and also the overall focus of the thesis can be better understood.

The term Russo-phone applies to the Russian-speaking population in Estonia. These may or may not be Estonian citizenry. Culturally, these people may identify themselves as Belarusian, Ukrainian, Russian, etc. The main idea is that they share a common language, and as such are bound together in a minority group. This term is used frequently throughout this text, and if misinterpreted, could lead to much needless confusion.

The most important term to understand in the context of this thesis is social cohesion. In very general terms as defined by the Council of Europe, "Social cohesion is the capacity of a society to ensure the well-being of all its members, minimizing disparities and avoiding marginalization." ${ }^{, 42}$ So then in what respect does education and education reform affect social cohesion? On a much larger scale, the European Union has been demonstrating the effectiveness of education on common identity through such EU-funded programs as ERASMUS. Why can these concepts not be applied on a smaller scale in Estonia? There are certain programs that exist such as youth groups and language immersion camps, but they are not nearly as popular or as promoted as the EU-wide ERASMUS. In fact the idea of governments using education as an instrument of socialization has been around for centuries. Mark Gradstein and Moshe Justman give a brief historical overview of this phenomenon in their article "Education, Social Cohesion and Econ. Group":

"The emergence of government intervention in schooling in the eighteenth and nineteenth centuries was closely tied to its socializing role (Harry G. Good and James D. Teller, 1969; Andy Green, 1990). Autocratic rulers in eighteenth-century Prussia and Austro-Hungary used it to

${ }^{42}$ Directorate Generale of Social Cohesion of the Council of Europe "Report of the High Level Task Force on Social Cohesion in the $21^{\text {st }}$ Century," http://www.coe.int/t/dg3/default_en.asp, last accessed 1-2-2011. 
strengthen their subjects' allegiance to the state. In nineteenth-century France and Germany, centralized schooling contributed to the forging of unified national identities. In Great Britain, the ruling elites viewed socialization of the working class through compulsory primary education as a necessary concomitant to the extension of the franchise (Albert V. Dicey, 1914). In the United States, the expansion of public schooling in the early twentieth century contributed significantly to the cultural and economic assimilation of large waves of immigrants (Newton Edwards and Herman G. Richey, 1963)." 43

Education as a socializing factor in the lives of Estonian and Russophone children living in Estonia is one of the main reasons why the Integration Strategy relies heavily on educational reform for its success. It is seen as one of the key ingredients in social cohesion, and leads to a well-developed sense of mutual understanding and appreciation.

Inter-ethnic attitudes and mutual attitudes among cultural groups are two different terms used in two of the texts cited for this thesis to describe the same concept. ${ }^{44}$ Simply put, these are the attitudes that one cultural group generally has toward a cultural group of a different origin. These can range from negative to positive to indifferent and are based on any number of personal experiences, media portrayals, and stereotypes. In this study, these terms can be used interchangeably referring to the attitudes and perceptions Estonians have of the Russo-phones and the attitudes and perceptions the Russo-phones have of Estonians.

\section{Literature Review}

Over the past two decades of Estonian independence, many studies have been done to enhance understanding of the challenges the society is facing daily in regard to the Russianspeaking minority population and the effects of the inherited Soviet system of their recent past. The following five studies have all contributed in one way or another to the body of research dedicated to the integration process, ethnic differences or education in Estonia. By reviewing these recent studies, I will try to provide a background for my thesis, which builds upon the work of my predecessors. These articles take on varied themes and the studies overlap in some areas; however, each contributes in different ways to the scholarship regarding Estonian reform. The

${ }^{43}$ Mark Gradstein and Moshe Justman, "Education, Social Cohesion, and Econ. Group," The American Economic Review,92, 4 (2002): 1193-1194.

${ }^{44}$ Korts and Berry use these terms, respectively. 
articles will be reviewed in chronological order, so as to note the progression of skepticism and theories regarding the capacities of the reform program.

In an article by Veronika Kalmus, we are introduced to the subject of an integrated Estonia with a critical eye. In her research study published in 2003, "'Is Interethnic Integration Possible in Estonia?': Ethno-Political Discourse of Two Ethnic Groups," Kalmus debates whether the possibility of an integrated Estonia exists due to the different discourses that can be seen among and between the two major cultural communities in Estonia-the Estonian and the Russo-phone. ${ }^{45}$ The study finds that the Estonians and the Russo-phones hold different national discourses, often quite opposite of each other. She goes on to imply that these separate ethnic discourses are a source of conflict in the relationship between the two groups. Citing textbooks, media, academic publications and historical influences on individuals' personal discourse, she shows that the underlying element to all of these factors is ethnicity. This seems to be a very valid critique of the reform program and it recognizes the challenges that such differing discourses would place on a society in transition toward integration. Her suggestion for fixing this problem is to create a new discourse for the Estonian society as a whole. Kalmus notes the importance of the educational system as a leading contributor to the construction of a new discourse that would apply to all people living in Estonia, regardless of their ethnicity.

Kalmus, with fellow author Marja Pavelson, co-wrote a different article in which they explain the importance of schools as socializing tools. Expanding on the concluding thoughts of Kalmus' previously reviewed article, "Schools in Estonia as Institutional Actors and as a Field of Socialization" argues that the educational system has a great effect on the discourses and contexts of the society. ${ }^{46}$ Within the context of the Estonian situation of new integration policies, they validate the Estonian government's heightened attention to this issue over the last decade. In recognizing the educational system as a means of socialization, and therefore a tool for integration, Kalmus and Pavelson justify the Estonian government's dedication to education

\footnotetext{
${ }^{45}$ Veronika Kalmus, “'Is Interethnic Integration Possible in Estonia?': Ethno-Political Discourse of Two Ethnic Groups," Discourse and Society 14, 6 (2003): 667-697.

${ }^{46}$ Veronika Kalmus and Marja Pavelson. "Schools in Estonia as Institutional Actors and as a Field of Socialization." From Marju Lauristin and Mati Heidmets (eds.) The Challenge of the Russian Minority: Emerging Multicultural Democracy in Estonia. (Tartu University Press, 2002): 227-236.
} 
reform. Balancing consideration of the past and its effects with the goals that the Estonian government has for its society, the two authors contribute something of great value to this field of study. The authors establish that within a school there can be found two different social agents, the dominant and the dominated, which are constantly struggling for power. The dominant agents are the teachers and faculty and the dominated are the students. The authors suggest that the dominant agents have a great influence on the dominated in the realm of socialization, and while it may be difficult to quantify, "compared to other factors such as family and media, the school is an important agent for transmitting political information to young people. The school is somewhat less central in shaping political attitudes and participation orientations, except for students from ethnic minorities or low status groups."47

This statement re-affirms the focus of this study, that the educational system is more influential in the lives of minority students, therefore signifying that educational reform, especially in regards to the Russo-phone population, can trigger changes on a larger scale in the society, such as the progress toward social cohesion. Kalmus and Pavelson's study was also completed in the early years of the integration process, and as such, is far more applicable to the theoretical aspect of the current situation as opposed to the practical aspect, as many changes have occurred since the study's publication. Even so, this article is both critical and informative, and a necessary addition to research regarding multi-ethnic education.

The American scholar, Mark Lapping, provides his commentary on how the post-Soviet historical background has created a stumbling block for education reform in Estonia. ${ }^{48}$ This study was published in 2004, at the mid-term of the first phase of the organized integration process. As such, this is an excellent example of the expectations that the global community held for Estonia and its new reform program. "Education in a Restoration Democracy: The Case of Estonia" is based upon the hypothesis that the changes being made in Estonia constitute a general success story when comparing their democratization to those of other post-Soviet or post-communist states. In the sense that this reform program had only been functioning for approximately a year at the time of publication of this article, Lapping's arguments that Estonia

${ }^{47}$ Kalmus and Pavelson, 230-231.

${ }^{48}$ Mark B. Lapping, "Education in a Restoration Democracy: The Case of Estonia." Citizenship, Social and Economics Education, 6-2 (2004): 101-115. 
has left its political past in the proverbial dust, the road blazed forward by reform, seems a little premature. Focusing on the Europeanization of Estonia and the emergence of "digital democracy," Lapping shows that Estonian reform of education was running concurrent with the transition to democracy and how they complimented each other. It should also be noted that although Lapping does pay attention to the potential problems of minority education, particularly in regard to the Russian sub-culture in Estonia, the article does not seem to view integration as something that could be contentious. With this general oversight, the author runs the risk of being too optimistic about the future success of the integration program.

Along the same lines as the previous article, a European scholar, Gabrielle Hogan-Brun, gives a more comparative approach to the Baltic States as individual entities within a regional model of parallel paths of democracy and education. In the article, "Language in Education across the Baltics: Policies, Practices and Challenges," Hogan-Brun takes a decidedly different approach than Lapping, noting the ethnic differences as an ever-present obstacle in the education reforms of the Baltic States. ${ }^{49}$ Giving a broad overview of the system and the changes being enacted, Hogan-Brun doesn't have much opportunity to expand on the particular situation in Estonia for more than a few paragraphs, which is a bit disproportionate to the amount of analysis she gives to the other Baltic states. That being said, she is still able to focus her concern on the Russian minority and the problems that arise from a multi-ethnic society whose goal is integration.

Kulliki Korts takes a look at the ethnic disparities in Estonia from a more sociological perspective in her research study from 2009. Her article, "Inter-ethnic Attitudes and Contacts between Ethnic Groups," goes a step further in the field and shows how children are not immune to the differing inter-ethnic attitudes of the greater society. ${ }^{50}$ By gathering essays written by students, she determines that inter-ethnic attitudes are more ingrained in society than most people assume. Particularly interesting is the timing of this article. It was written only a few years after the very public and violent resurgence of ethnic issues in Tallinn regarding the Bronze Soldier statue in 2007. Korts pays particular attention to the integration aspect of this events noting that

${ }^{49}$ Gabrielle Hogan-Brun, "Language in Education across the Baltics: Policies, Practices and Challenges," Comparative Education, 43-4 (2007): 553-570.

${ }^{50}$ Korts, 121. 
the government emphasized the implementation of the integration strategy over inter-ethnic attitude awareness. She contemplates that if the focus had been on rehabilitating inter-ethnic attitudes, then integration would have gone more smoothly.

These five examples of other authors' contributions to this topic show the wide range of possible conclusions that can come from relatively similar information, as well as how quickly the information and analyses can become obsolete. This thesis will build on what has been done in previous years, taking into account the scholarly articles and studies that are relevant to the topic of educational reform in post-Soviet Estonia. The data gathered for the purposes of this thesis and the consequential analysis will provide insight into facets of this field of study not yet tackled in previous articles, such as the implementation of immersion programs, geographical needs regarding resources, and the impact of education on social cohesion in Estonia. 


\section{CHAPTER THREE: Methodology}

The methods used in gathering and analyzing data for this thesis are primarily qualitative in nature. In some cases, statistics and percentages are used in correlation with personal observations and experiences; however, the large majority of the research employed in this thesis is subjectively analyzed. The two methods of data collection specific to this thesis are personal interviews and case studies. Along with surveys and statistics available to the public, the data gathered from specific educational environments, i.e. the case studies (individually), are juxtaposed with Berry's four preconditions. These will also be applied to Estonia's strategic plans for integration on the national level. In this way, the hypothesis can be tested on a practical level by means of the case studies and the interviews conducted.

\section{Interviews $^{51}$}

In total, twenty-five personal interviews were conducted. All of the interviewees are to be kept anonymous and were told this before every interview to encourage free and direct responses. All of the interviewees were asked the questions, "What is your opinion on educational integration programs in Estonia?", "Do you think that there is enough communication between the cultural groups of Estonia?", "Do you feel tension between the cultural groups of Estonia?" and "What are your expectations of educational integration programs in the future?"

The interviewees were categorized according to their relationship to the educational system and their involvement in the process of integration, and questioned similarly within the group structure. Six of these interviews were current students, who were specifically asked, "What are you educational plans for the future?" Seven of the interviewees were former students who graduated after Estonia re-gained independence. These persons were asked additional questions such as "What is a distinct memory you have from school?" "What suggestions might you make to create better educational environments?" and "How prepared

\footnotetext{
51 Texts of the individual interviews can be found in Appendix C. Texts of interviews conducted at school visits can be found in Appendices E, F, and G. Texts of interviews conducted with government representatives can be found in Appendix B.
} 
were you if and when you entered university or higher education?" Six of the interviewees were faculty members, and were specifically asked "What were the more difficult changes during reform?" and "What are the most distinguishable effects you can see from educational integration programs?" Three interviewees were older citizens, and they were asked, "What particular educational memories do you have from before Estonia re-gained independence?" And, finally, three interviewees were government representatives and they were asked to explain government-supported programs, such as how immersion schools were selected and how the programs have changed over time.

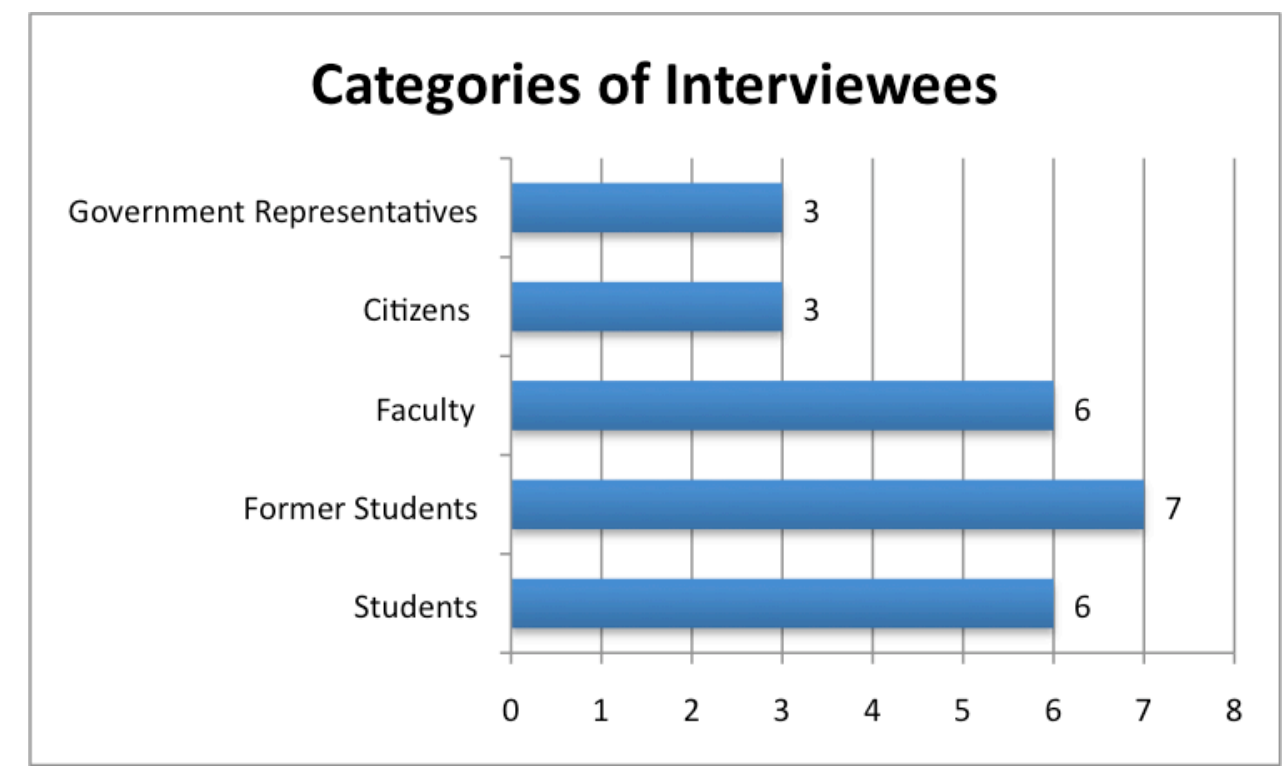

Figure 4

Demographically, the interviewees ranged in age from 17-82, six falling in the "under 18 " category, six in the 18-25 range, three in the 25-40 range, nine in the 40-60 range and one in the $60+$ category. 


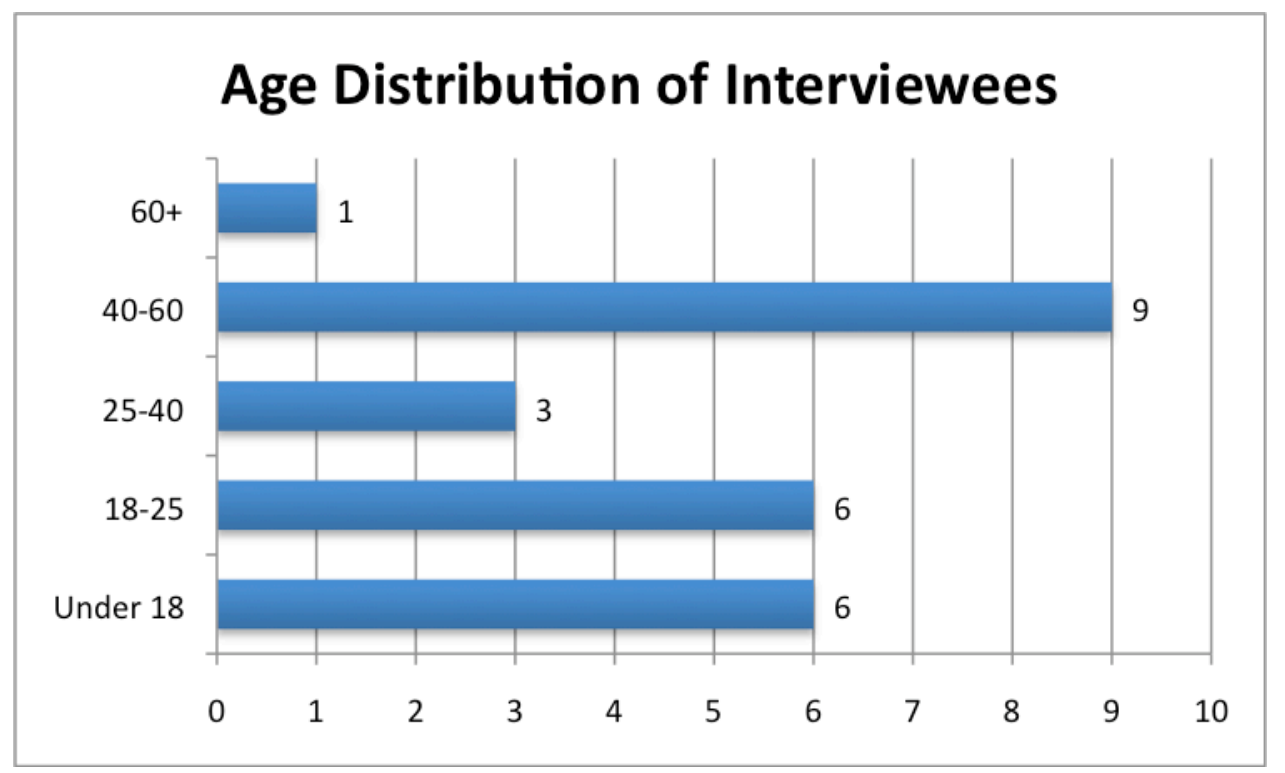

Figure 5

The interviewees were relatively evenly distributed among cultural groups with thirteen Russo-phones and twelve Estonians.

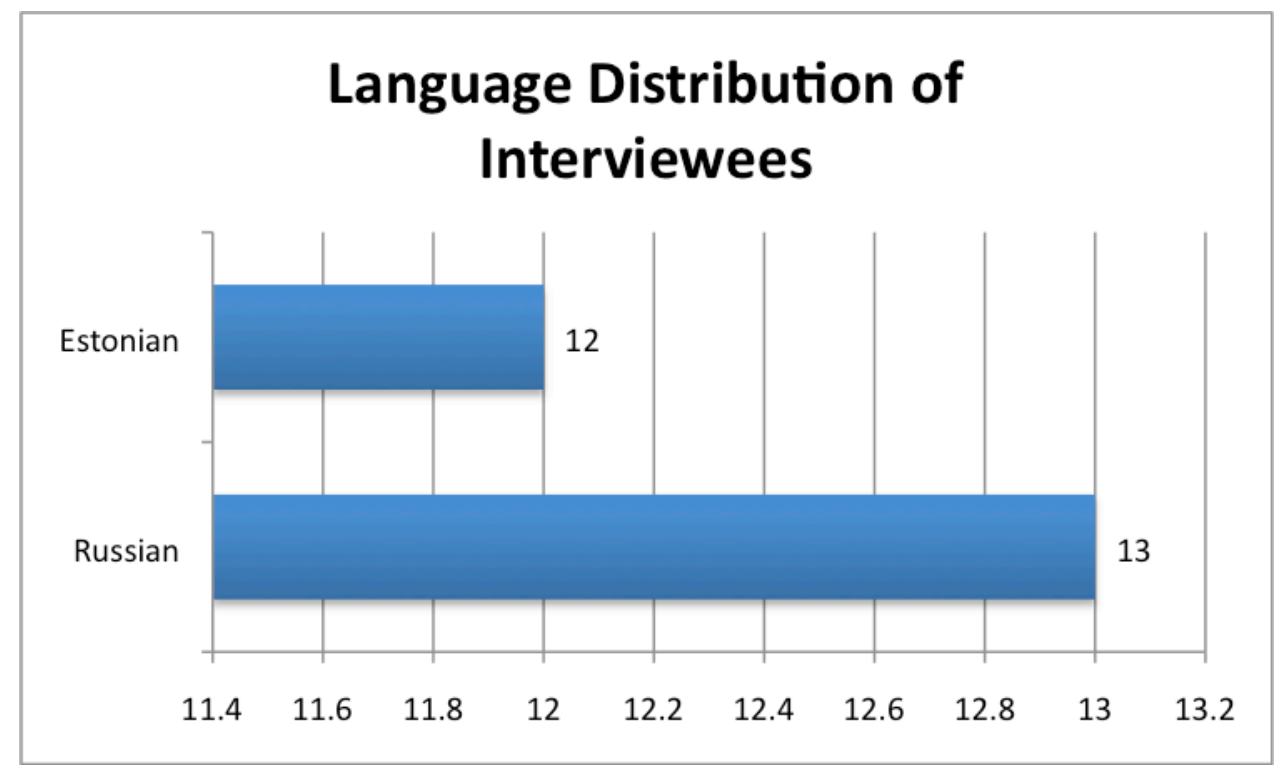

Figure 6

Unfortunately, the sample was less evenly distributed by gender, with sixteen female and nine male interviewees, although it is unlikely that this will influence the results. Like most 
elementary and secondary educational systems, the ratio of female teachers to male teachers is not balanced, and this is definitely a contributing factor to the bias. Most of the interviewees were school employees or affiliated with the educational system (faculty members, directors, and students of secondary schools) in some way, so as to provide expertise and relevant personal experience. As stated before, anonymity of the individuals interviewed is very important, and therefore the schools attended or where the individuals are employed cannot be distributed, but the texts of the interviews are available in the appendices. Due to the gender imbalance inherent to the system, the results of the skewed gender ratio of the interviewees corresponds with environment, which will most likely make the findings more accurate than an equal ratio of female to male interviewees would. ${ }^{52}$

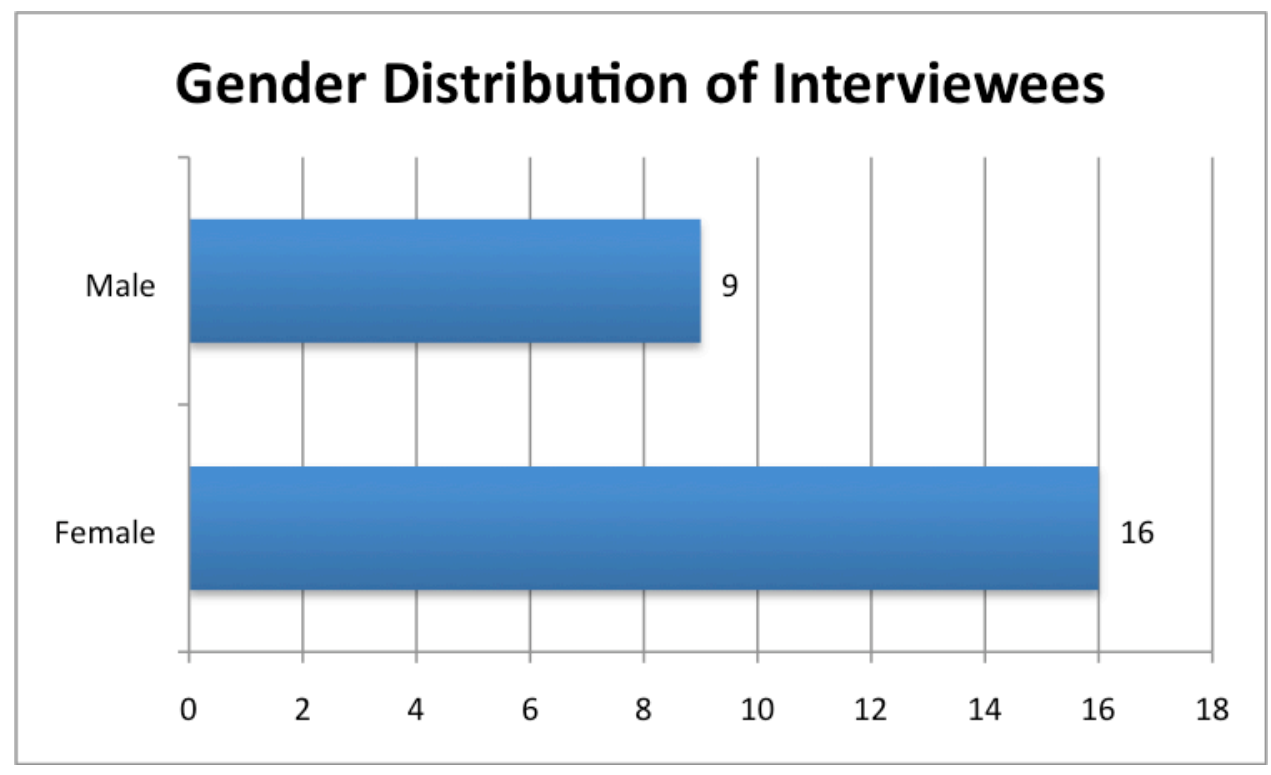

Figure 7

${ }^{52}$ As in many countries around the world, including the United States, there is often an unequal ratio of female teachers to male teachers in grades K-12. This could be due to many factors, among which are occupational coding, the fear of sexual harassment, etc. The most appropriate reason for the uneven gender distribution in the primary and secondary teaching positions is most likely the former rather than the latter. Primary and secondary teaching positions are stereotyped by society as being "female jobs." 
The ways in which the interviews were conducted is also a very important aspect. Nineteen of the interviews were conducted in person, which allowed for more of a conversational feel. This style of interviewing is likely to cause more candid responses and allows for non-verbal communication. In the six interviews conducted via e-mail, it can be assumed that there was more deliberation before the responses were written and submitted, which could mean that the responses are more in-depth than they might be had they been conducted in person, or potentially more politically correct. Another way in which the interviews differed is by language. All the questions were asked in English, but four interviewees needed the help of a translator in order to respond. Two required translation into Russian and two required translation into Estonian. The translators were not chosen by the conductor of the interview, but were established on site.

\section{Case Studies}

Three case studies were conducted. All of the schools participated voluntarily with an understanding of the study being conducted, however the names of the schools are not pertinent to the study and therefore will remain anonymous. Each school was requested to participate because they employed Russian language in their school and because of their location in Estonia-each city is geographically significant, as well as being among the three most populated cities in Estonia. All other variables, i.e. language immersion programs, were not examined until on site.

Along with interviews with faculty members and directors, two of the three schools allowed for student interaction with the interviewer. One school in particular allowed the interviewer/researcher to tour the building and attend a school assembly. These insights into the school's inner-community and environment were not requested, but offered, and as such, cannot be expected of the other schools participating in the case studies. Other peculiarities, however, such as the language that the questions were being translated into and initial reception will be noted for analysis. After every visit a journal entry was made, portions of which will appear in the analyses. Due to the interviewer/researcher's "outside observer" status in each school, the type of interaction experienced during the interviews, non-verbal communication and other 
anomalies should be noted and analyzed in order to understand the school environments better and also to aid self-critique.

Statistical data comparing each school's test results to the national average will be taken into consideration when analyzing the impacts of education reform. Four indicators ${ }^{53}$ in particular will be highlighted: the number of students, scores in national language, Estonian, and Russian language, graduation rates of grades 9 and 12, and teacher evaluations. The scores will be compared to other schools in their area as well as to the national average to determine if geography and demography play roles in this determinant.

\section{Limitations}

One of the most obvious limitations to this study is the researcher's heavy reliance on English sources to compile data. Interviews were often done through translators and therefore there is a lot of trust placed in the translations. Small nuances in language have the possibility of being misinterpreted, even though necessary precautions were taken to simplify the wording of questions. Also, the researcher had to rely on her less than adequate Estonian and Russian language skills to personally translate certain documents from the Estonian government, newspaper articles, and other sources. This creates the possibility that certain texts could have been translated poorly or even incorrectly.

A potential neutralization of this language barrier is that the researcher did not have any personal biases in regards to language, ethnicity, or otherwise to the subjects and issues involved in her research. By having no attachments to any particular ideal, her analysis has the potential to provide a fresh look at a problem than perhaps Estonians and Russo-phones in Estonia have not had the ability to perceive because of their personal backgrounds.

\footnotetext{
${ }^{53}$ These indicators are required for all students in Estonia, no matter the ethnicity or the language in which they are educated, except for Russian language, which can be tested as a "maternal language" for Russian-speaking students or as a "foreign language" for Estonian speakers. There is no distinction made in the statistical data that separates these two categories for learning Russian.
} 
Another limitation that could be said of this research is that the pool of opinions generated by the interview process was relatively narrow. Some might say that it is impossible to conceive of gaining a breadth of knowledge about the Estonian society and its citizenry from so few people. Although the researcher concedes that a larger body of interviewees would have been favorable and most likely would have provided a greater insight into the issues being addressed in this thesis, there were time constraints, language barriers and physical barriers, which made her attempts at widening the perspective of her research more difficult than was foreseeable. Also, the range of demographics, specifically distribution across ages and ethnicity, covered by the interviewees is substantial, considering its size. 


\section{CHAPTER FOUR: Case Studies}

With a developed theoretical framework by which to analyze the policies and progression of education reform, this section will outline the three case studies that contribute to the practical application of this research. The information contained in this chapter will also be used in the analytical chapter, where the three schools will be assessed individually, comparatively, as well as collectively. Each school, for the purposes of this study, is to be seen as representative of a particular phase in the reform process. It is necessary to understand that there are inequalities present in any school system, and that Estonia is no exception. Differences can be seen, whether demographic, economic, geographic, or other, that all contribute to the resources that are available to each school and, obviously, composition of the student body. Each school has strengths and weaknesses, and these will be taken into consideration as much as possible for the period under analysis. For simplification purposes, it is easiest to view the spectrum of reform as a line. On one end of the line, there is- "no reform" on the other, the end goal of Estonian educational reform-"social cohesion," with multiple steps that may be interchangeable in between:

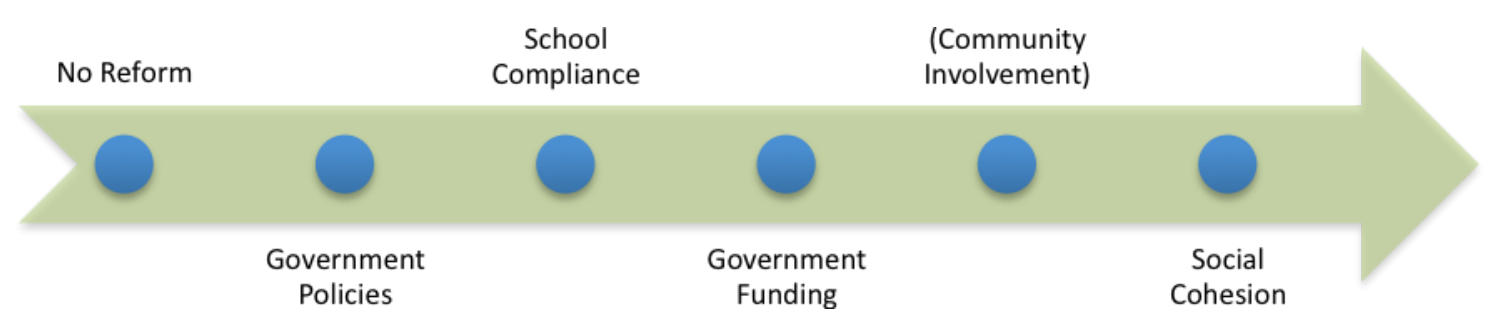

Figure 8

The phases that will be touched upon by outlining these three particular schools are: the example from Tallinn - school compliance with government mandates, little action taken beyond requirements; the example in Narva-school compliance and new government funding for early 
language immersion program; and the example in Tartu-school compliance, well-established government-funded late language immersion program and newly-established early immersion program. These three schools all show progress towards Estonia's goal of social cohesion, but the extent of their progress corresponds with their location, their resources, and their relationships with their surrounding communities and the Estonian government. In each section, there will be an overview of the region, followed by an explanation of the types of reform implemented, if any, and finally an account of the researcher's experiences at each school and her impressions.

School selection was based on advice given by a professor at the University of Tartu after the researcher explained the study's goals. The researcher attempted to contact over 25 different schools to request their permission to visit and interview the director, a few students and perhaps faculty members. The case studies presented in the following pages represent three schools that were not only open to a visitation, but also held various geographic locations of interest to the study. For the objectiveness of the study as well as protecting the identities of those who offered their time and experiences to help in the study, all the schools and individuals will remain anonymous.

\section{TALLINN CASE STUDY}

The capital city of Estonia, Tallinn, is the most populated and most diverse city in the country. With over 410,000 inhabitants, half of whom are Russian-speaking, the integration process and its progression is of vital importance to the well being of the city. This diversity can be seen in the simple juxtaposition of the beautiful Russian Orthodox Alexander Nevsky Cathedral with the pink Estonian Parliament building in Toompea Castle. It is interesting to note that in $2009,22 \%$ of Tallinn's population did not have EU citizenship. ${ }^{54}$ In fact, a significant number of Tallinn residents are citizens of the Russian Federation.

The reality is that these facts can put a strain on the government's aims at social cohesion. In 2007, the capital city made international headlines as a result of the ethnic tension that had erupted over the repositioning of The Bronze Soldier statue, which held particular

54 Tallinn Statistical Yearbook of 2010, http://www.tallinn.ee/est/g2677s51324 
significance for the Russian-speaking community. Although this city has abundant resources, as it is the capital and one of the biggest ports in the Baltic Sea region, the road to social cohesion is not going to be easy. Even after a decade of solid work done in the Russian-language schools by the Ministry of Education, which has introduced policies to facilitate the building of ties between the linguistically separated communities and has attempted to ensure compliance, the case of the school located in the capital city of Estonia is not leading the way to reform.

The school is located relatively close to the city center. This location is significant because of the proximity to the site of the demonstrations and protests of 2007, which were very controversial events in Estonia. One might expect to perceive a nationalistic tone during the interviews and tour of the school, due to the neighborhood's recent history, but this was not the case. Unlike the other schools visited, there was no Estonian language immersion program in place at this particular school in Tallinn. Language immersion, as mentioned in Chapter One, is the method of bilingual education most supported by the Integration and Migration Foundation, Our People - the methods that are used to implement this in the schools will be touched upon in more depth later in this study. Surprisingly, though, the school in Tallinn had the highest test scores for Estonian language out of the three schools studied. This is likely due to the selectivity of pupils that the school admits. This school is well known for it's highly competent math and science scores, but overall is a highly competitive school. Also, students perhaps have more of a chance to practice their language skills being in the capital city, surrounded by half of the population that speaks Estonian as their mother tongue.

The researcher recorded her impressions in a personal journal for the purposes of conveying the experience to outsiders. The interviewer's role within the setting should be noted as formal but casual and by her own words:

"I was greeted with Russian at the door and I introduced myself and asked if the director was ready for me. I was invited in, and the director soon came to greet me. I was then taken to an empty classroom, where two students and two teachers were also there to contribute to the interview. I felt very welcomed, and they answered all of my questions very honestly, it seemed. They were not afraid to voice their opinions and they commented freely on their experiences with the integration process." 
The interview ${ }^{55}$ was translated from English into Russian for the director and the other participants relayed their opinions in English. When asked about the problems of integration, the respondents had different opinions. The director and her fellow faculty members lamented the fact that so many teachers had lost their jobs because they didn't speak Estonian well enough. Especially for older teachers, this has been a major issue. They also mentioned that they still do not have a teacher capable of teaching History in Estonian, one of the subjects being stressed by the Estonian government as vital to the integration process. The director and teachers who have been there since the collapse of communism mentioned how difficult the reform was in the beginning. The director stated that, "The curriculum had completely changed, and the ability to provide a quality education in Estonian was a very big problem." The situation improved dramatically, they said, when more attention was paid to providing new books for students in Estonian and translated versions of Estonian books into Russian so that the subject matter taught in all schools was the same. In general, their outlook on the situation was positive, but they admitted there was still a long way to go.

The students were more concerned with the different terminology in specific courses. This school focused primarily on math and science-related subjects, and the idea that they might have to transition into the Estonian-language versions seemed daunting. One of the teachers was quick to point out that their graduates recognize that they need Estonian, and that they have different projects with other Estonian-language based schools in Tallinn to help with communication. One of the students participating in the interview mentioned that she had attended one of these other Estonian schools for a week-long exchange. She said that she had been excited at first to try something new, but then was not received well by the Estonian students. This further proved to her the cultural differences between the two communities; she noticed that the Estonian students didn't talk to her when she was in their class, and the Estonian student who attended her school "didn't try" to communicate with her classmates at the Russianlanguage based school. This reluctance to engage in inter-ethnic communication can be a hard barrier to overcome in the integration process. The interviewer noted in her journal entry:

"On the topic of identity, a contrast came up between the students and the teachers, which I thought was odd. The students said that they felt very Russian and that being Russian was very

55 Text can be found in Appendix E. 
important to them. One teacher mentioned that when she would visit friends and family in Russia, it didn't feel like home just because she speaks the language. She said that she feels that being European is more important than being Russian. I found this to be very revealing of the Russian sub-culture in Tallinn.”

One particularly interesting thing about this school is the attention it pays to extracurricular activities. The students have taken part in international competitions, trips to St. Petersburg and Brussels as well as around Estonia and the other Baltic States. Its website states that the school provides an Estonian Culture class that other schools don't have, and the things they learn in this class are supported and reinforced by these trips around Estonia. Similarly, the trips to St. Petersburg are meant to reinforce the subject of Russian literature and trips to Brussels to reinforce classes focusing on social sciences.

\section{NARVA CASE STUDY}

As a city that is known for its border with Russia, the influence that the proximity of the former "big brother" has on the current culture and the people of Narva is quite apparent. The majority of the population of this region, Ida-Virumaa, speaks Russian. In fact, although the population has been steadily declining for the past five years, this third most populated city has a Russian speaking population of approximately 93\%. ${ }^{56}$ Another anomaly, in respect to its residents' citizenship, is that over half of the population of Narva does not have citizenship in Estonia. To be specific, 35\% are citizens of the Russian Federation, along with small percentages of Ukrainians, Belarusians and Finns ${ }^{57}$, while another $17 \%$ of the population has undetermined citizenship.

In general, it is not the most conducive environment to implement an integration program aiming at school immersion in Estonian language. That being said, this does not mean it is not being attempted. The type of immersion program being implemented by the school of focus in Narva is called early-language immersion. In order to start such a program at one's school, the Integration Foundation requires compliance with 10 criteria before undergoing any immersion program. They are as follows (roughly translated):

\footnotetext{
56 Narva in figures, 2008, http://www.narva.ee/files/Narva arvudes 2009 est en.pdf.

${ }^{57}$ This is in reference to citizenship.
} 
1. The school is a municipal school.

2. The school has intensified the experience in the field of Estonian language.

3. The school has an agreement or a clear vision of how to ensure the immersion program qualified teachers contracted for future years).

4. The school has an experienced teacher learned in the methodology of teaching in Estonian and teaching Estonian as a second language.

5. Development of the school's curriculum is reflected in the acquisition and gradual expansion of Estonian for non-Estonians.

6. The school's courses are offered in a focused and consistent manner.

7. The school has the basic necessities (classrooms and furnishings suitable for teamwork).

8. School management is aware of the principles of language immersion.

9. The school is willing:

a) To explain the immersion program to both the schools and the community.

b) Foster teamwork within the whole immersion group.

c) Introduce curriculum changes.

d) School managers and teachers to continue from year to year.

e) School managers and teachers are to participate in missions of teaching time, creating an interactive environment for the students.

f) The school must cooperate with program partners domestically in programs like exchanges, and abroad at various conferences. 
g) The school should agree to share experiences with the immersion community.

10. The school employs a person specifically for writing grants regarding the immersion program. $^{58}$

The early-language program can be started in the first form, at which point all subjects will be taught in Estonian. Currently, more students are involved in this type of language immersion program than any other throughout Estonia. Gradually Russian-language is added back into the curriculum over the years, along with a foreign language. By the sixth form, the students are receiving an equal amount of class time in both Estonian language and Russian language. The proportions of classes being taught according to the language of instruction can be seen in the graph ${ }^{59}$ below:

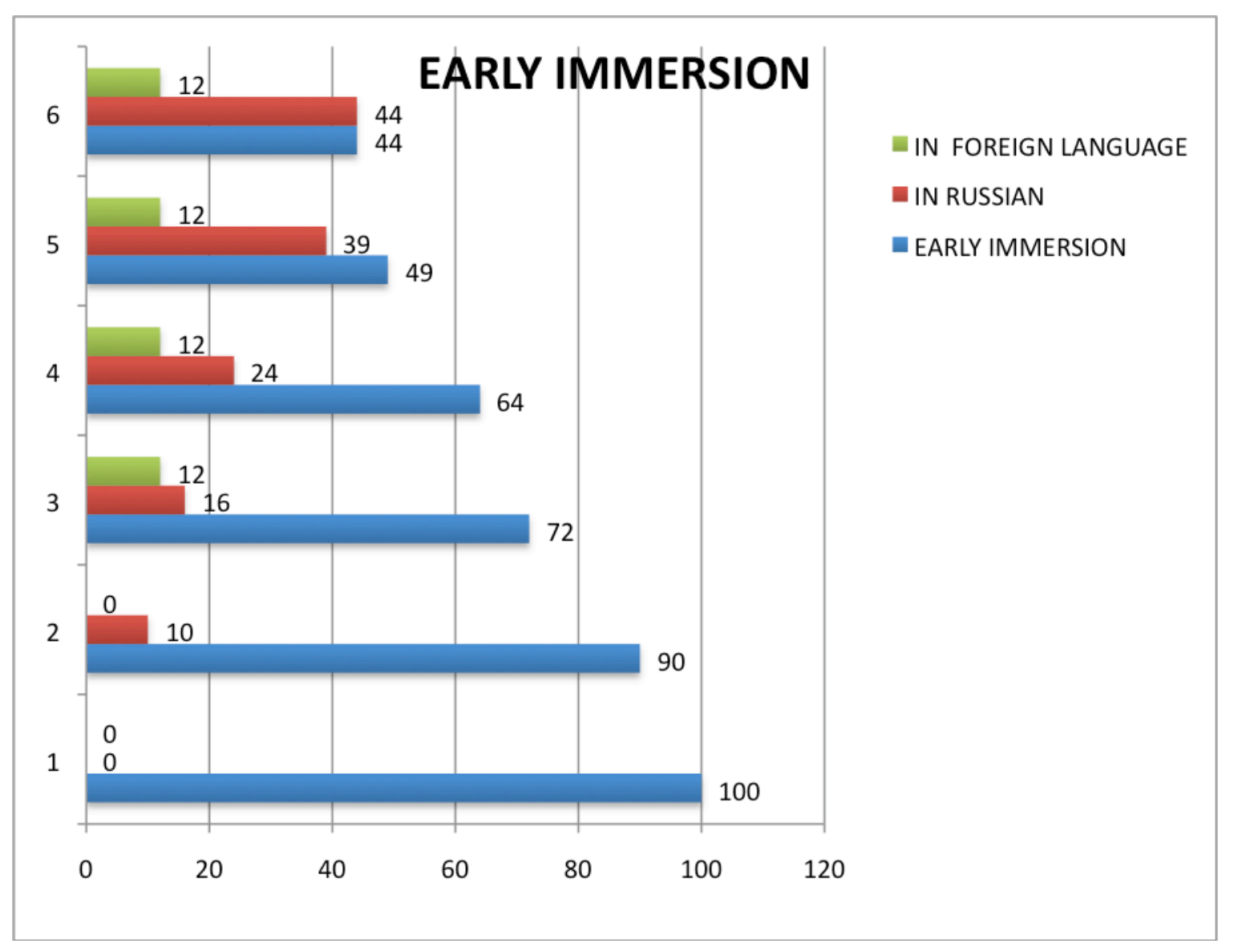

${ }^{58}$ Hiliskeelekumblusprogrammi koolide valiku kriteeriumid, 2004 (Google Translate)

${ }^{59}$ Ten Years with the Language Immersion Programme, Keelekumblusprogrammi rahastab Haridus-ja Teadusministeerium (2010) p. 49. Original graph transcribed for clarity. 
Figure 9

Interestingly enough, the school that was visited had only just begun offering an early Estonian-language immersion program as an option for some students. Even more interestingly, this school's scores for the leaving examinations have generally been higher in the subject of Estonian language than at the school which is the focus of the case study for Tartu that has been offering late Estonian-language immersion for a few years longer. In fact, the school that was visited is the only secondary school in Narva whose scores in Estonian language have been higher than the national average, with the exception of the most recent year. To be fair, all scores for the Estonian-language exams of the schools researched in Narva have decreased from 20062009. The scores of the school visited still managed to exceed those of the school offering the late immersion program. As the new program has just started, gathering the opinions of the young learners would not have proved to be very instructive; however, it would be very interesting to return in a few years to see the progress that might evolve at the school, and in the community as a result.

The early immersion program at this school is a superb feat in and of itself. The director $^{60}$ mentioned that parents of the students had been showing interest in such a program, and although the program is not state-funded, like the late immersion program at one of the other schools in Narva, it was seen as an important improvement that aids the school's progress. According the interviewer's recording in her journal:

"The director was kind enough to entertain my questions, but didn't share his opinions as much as I was hoping he would[...] He mentioned that the program was school-initiated because of the community's interest, and the director and the English teacher both seemed very enthusiastic about the progress they were seeing in the students and hopeful about the future of the program. One thing that the director was very adamant about was the need for more funding from the state. He mentioned an organization in Tallinn, which he found to be a very important to be consulted for advice before and during the implementation of the new immersion program, but there was no financial means of support."

Although still not reaching the Estmark for percentage of teachers who have passed Estonian qualifying exams, ${ }^{61}$ this particular school beats its competition in this area, with a

${ }^{60}$ Text of interview can be found in Appendix F. 
percentage of $99.4 \%$, the Estmark being $100 \%$. Having qualified teachers is an essential part of the educational reform, and the director mentioned that in an area where Estonian is not the majority of the population's first language, this has been a particularly difficult requirement to meet.

\section{TARTU CASE STUDY}

The city of Tartu is the second most populated city in Estonia, and seemingly the best environment out of the three cases studies for an established integration program to flourish. Situated in the southeast of Estonia, the city is home to roughly 100,000 inhabitants. Around $20 \%$ of the population is Russian-speaking and the University of Tartu has many courses taught in English and Russian, contributing to the multicultural atmosphere of the "City of Good Thoughts." ${ }^{62}$ With the exception of some significant Russian Orthodox churches and Russian cuisine-themed restaurants, the presence of the Russian-speaking community is not as obviously felt as in Tallinn or Narva. Estonian language skills are much more essential for everyday life, and as such, the success of immersion programs, such as the one in the school being studied, have a a greater impact on the students, faculty and community as a whole.

The late-language immersion program, which is supported by the Integration Foundation as well, is structured differently than the early immersion plan. The students are introduced to studying more subjects in Estonian, such as History and Social Sciences, in the sixth form, while they are still being taught primarily in Russian, again with the additional foreign language. In the seventh form a drastic change occurs and the majority of classes are then taught in Estonian, with only a few courses being taught in Russian. This plan remains steady through the eighth and ninth forms. A visual example of this can be seen in the image ${ }^{63}$ below:

\footnotetext{
62 Tartu in figures, 2009, http://info.raad.tartu.ee/teated.nsf/0/6EB55BC13DEC7375C22575890039E4A4/\$FILE/tartu_arv udes 2009 ENG spread final.pdf

${ }^{63}$ Ten Years, 49. As with the previous chart, the original has been transcribed for clarity.
} 


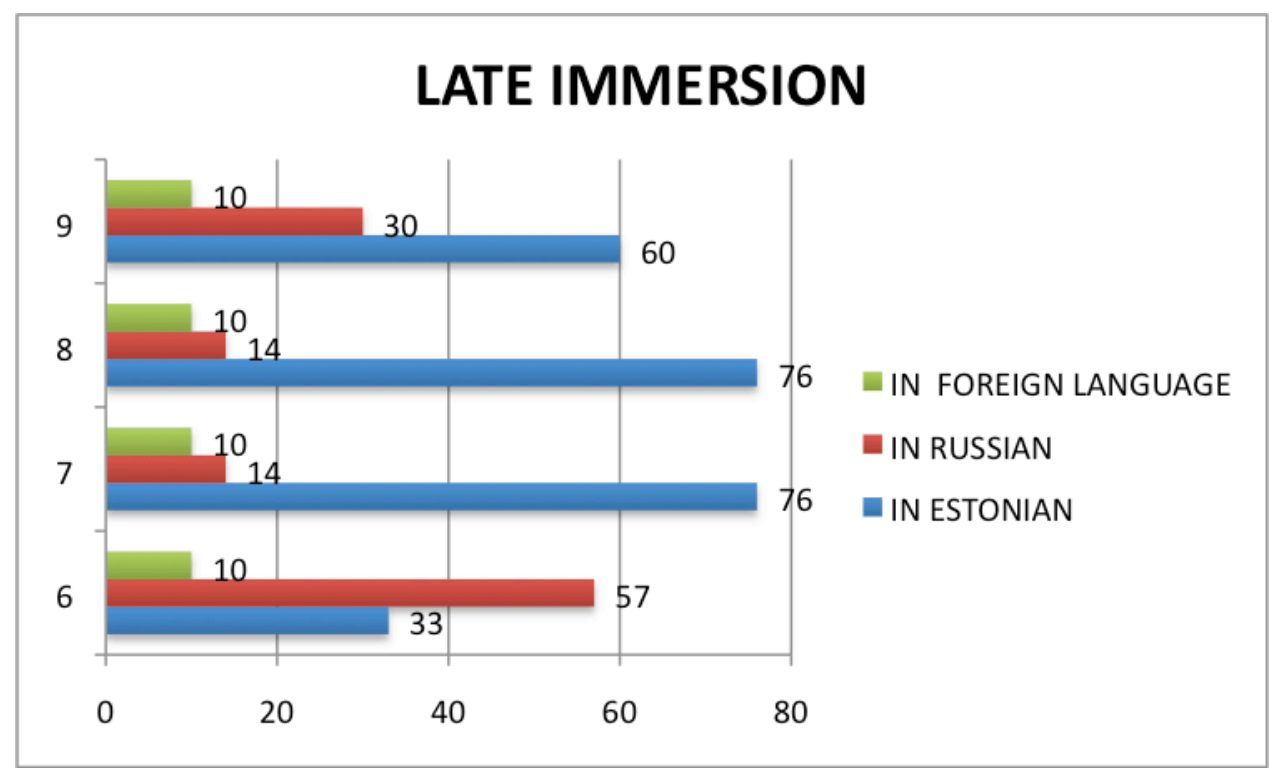

Figure 10

With the new Strategic Plan from the Estonian Ministry of Science and Education, the continuation of the 60/40 study formula will be gradually implemented at all secondary schools by $2011 .^{64}$ It would therefore seem that students already familiar with this format due to latelanguage immersion programs would make this transition much easier than those who have not experienced such a curriculum.

The school in Tartu was the only one of the three schools visited which had a state funded late-language immersion program in place as an option for its students. With the seat of the Ministry of Education and Research as well as the prestigious University of Tartu situated close by, there is an abundance of resources available to this school. The director has done much research personally on the development of immersion curricula, and as the head of the school she is an excellent representative of the openness and willingness that is necessary for integration to come to fruition. By inviting two of the best students from the late-language immersion class to

64 "Strategy for General Education System 2008-2013," Minstry of Education and Research, Government order no. 26, dated January 19, 2007; "Estonian Integration Strategy, 2008-2013," 28. 
be her translators, the director ${ }^{65}$ was able to show the advancements the school had made through individuals as opposed to facts and numbers. The interviewer noted:

"In the director's office, I felt very welcomed, and I only had to wait a few minutes until the student translators came to join us. They all explained the immersion program to me, and were very enthusiastic about the results of the program. The students were very involved in the discussion and their out-going natures and their English skills impressed me. After the interview, the students took me on a tour of the school and they spoke about the places they want to study in the future and what kind of music they like to listen to. I was taken to the choir room where a group of younger students were practicing a Russian folk song, and then to the library where the majority of the books were written in Estonian. The environment was very open culturally it seemed. The students then invited me to sit in on their math class as well as the school's assembly that they were performing in. The Minister of Culture was at the assembly to talk about the up-coming currency change in both Estonian and at times Russian, in order to ensure understanding. After the assembly I observed the interactions between the teachers and the students and they were able to talk freely in Estonian and Russian. Overall, I was very impressed with the school in Tartu."

The Tartu school has a strong attachment to the community and commitment to bilingual education. The school has been working with the Ministry of Science and Education since the 2001 in helping to compile research data. More recently there have also been developments for the implementation of early language immersion (which the interviewer was not able to witness first hand or retrieve the statistics). All of these factors prove that this school is really ahead of the curve, and is moving rapidly towards the goal of social cohesion.

Each school has something very unique to contribute to this study. With the various levels of immersion programs, attitudes of the individuals interviewed, geographical peculiarities and community involvement, we can see a wide range from stagnation to progress toward integration and social cohesion. By juxtaposing what has been seen with these case studies in regards to Berry's pre-conditions for multiculturalism to function properly, alongside the other interviews conducted in researching this subject, an analysis can be drawn as to what successes and/or failures have come from the government mandated strategies for integration in Estonian educational reform.

65 Text of interview can be found in Appendix G. 


\section{CHAPTER FIVE: Interviews}

\section{Perspectives and Expectations}

In this chapter, different perspectives will be examined. These perspectives on integration, contact between ethnicities, general communication and positive or negative impressions have been garnered from personal interviews and media sources for the most part for the sections on "Estonian" and "Russian" ${ }^{, 66}$ perceptions. These are the two major groups that populate Estonia, and as such, their perspectives on the issues surrounding integration in general and educational reform specifically are essential to proper analysis of the situation. The opinions gathered from the interview process will be taken collectively, so that one person's views will not hold any more weight in the analytical process than the others and a spectrum of ideas and opinions can be seen. In the cases where a quotation is given, the interviewee's age, gender and region will be offered to provide a context by which to view the opinion. For example, a Estonian-speaking teenager from a rural region might have less knowledge of the integration process because of inadequate exposure, whereas an Russian-speaking adult from Tallinn might have a more observable bias in his or her responses to questions regarding language requirements. Again, the views expressed in this section are to be seen as representative of the broad spectrum of ideas and opinions in society and across the many demographic differences of the interviewees, and not as fact.

\section{Estonian}

This study was fortunate that interviews with Estonians could be conducted from a wide range of age groups - from 17 to 82 - as well as from a variety of regions, from small towns all over Estonia with a variety of demographic distributions. As the topic of ethnic relations and inter-ethnic communication can sometimes be seen as controversial, a few of the interviewees declined giving an answer to questions regarding integration. Other interviewees stated that they were not familiar with the integration program and therefore could not give a solid answer. Most

${ }^{66}$ To be clear, the term "Russian" is used here not to define citizenship but ethnicity and culture. 
of the interviewees were at least willing to share their own personal experiences with Russians but declined to make generalizations.

There were very few Estonian interviewees who gave openly negative responses about the Russian population, and surprisingly enough, they were from the youngest age group. These were also the participants who were the least familiar with the integration process, one girl from Rakvere saying that she had "never even heard of it."67 Aside from such comments the interviewees in the youngest age group seemed ambivalent and untouched by the integration process. Factors for this could be their relative lack of contact with Russians, their age, or their location in Estonia and its demographic construction. The young adult group, from around age 23-35, seemed to take the most interest in the subject matter and have the most even-tempered and considered responses to the questions asked. Having essentially grown up during the tumultuous time of transition after a very emotional revolution, their broad range of experiences vary depending on the region they inhabit, and the amount of contact that they have with Russian-speaking individuals or groups. A student at University of Tartu, who is originally from Haapsalu, mentions how different the regions are when he travels back and forth. His expectations are different for each region. As the 23-year old explains it: "There is always contact with Russians when I go home, whether it is someone asking me for directions, or I need to buy something at the store. The Russian-speaking population in Tartu seems far more integrated by necessity. Even though, the eastern part of Estonia is still Estonia, no matter if it is mostly inhabited by Russians." This sub-group identifies itself more towards the global or European perspective than the others, trying to gain more information about the topic and forming their own opinions, but at the same time this group is not so unique that it does not still have the very distinctly Estonian vantage point like the others.

In mentioning this to the older participants, they responded that it is most likely because they have more training with Russian language than their younger counterparts, and so communication is not always as difficult for them. The oldest interviewee was quick to recount her memories of Soviet times. The 82-year old woman from a city outside of Tallinn, the name of which she did not disclose, shared that Soviet times were good for her family, but that the

${ }^{67}$ Appendix C 
same experience was not shared by all. When asked about the Russian school system, she decidedly stated that it was necessary, because "[Russians] don't want to go. Some were born here, maybe." ${ }^{, 68}$ She didn't seem to find it to be a problem, but said she could understand that idea of educational reform. When she reflected on the history of the territory and mentioned that Estonia had once before been an independent state, the idea that the Russian schools would be slowly incorporating more and more Estonian into the curriculum seemed to be accurate from her point of view.

In any respect, these few interviews had a certain common vein that ran through themit's not the Estonians' job to integrate, but the Russians' job to be integrated. And as the majority, this theme is common among other cultures facing similar problems. Contact between the Estonians and Russians varies according to location, but only a few of the interviewees cited lack of contact and communication as a problem for the larger society. These perspectives, while not exactly negative in nature, are also not wholly positive. Indifference from the majority group can be interpreted as negativity by the minority group, and this has been the case in Estonia, as can be seen in the following paragraphs highlighting the Russian perspective.

\section{Russian}

As far as Russian interview subjects are concerned, only three major regions are represented: Tartu, Tallinn, and Ida-Virumaa. The age-span is also more narrowed, making it more difficult to break down the subjects into age groups. The younger age group includes interviewees as young as 16 up to the age of 35 . The older group only ranges from 36-65. In general, the younger group was more open to answering questions about school integration and inter-ethnic tension, and the older group was more interested in answering questions about general problems of communication or identity formation.

When asked about the changes that one interviewee from Tallinn, aged 24, remembered from childhood, she responded that, "It was like living in two different worlds - first you are born into Soviet Union and then suddenly we understood that we are a part of Europe. Most of my childhood was still spent in Soviet Union, even though I was just 5 when Estonia became

${ }^{68}$ Appendix C 
independent, our mentalities stayed Soviet for a long time..." ${ }^{69}$ It also seems from the interviews with the younger generation that they see much more violence and tension focused on ethnic differences than the older generation. But of course, these same interviewees say that the amount of inter-ethnic violence highly depends on the region. The same Tallinn native noted that, "On the one hand I see younger generation being more aggressive to each other, on the other hand in some places it's not even a problem anymore." The older generations seem more concerned with the idea that through the integration programs, ethnically Russian children will be losing a part of their cultural heritage. One man in particular noticed how this was more common in places where the Russian population is not so prevalent. Originally from Narva, the 38 -year-old has been working and living in Tartu for over 6 years, and is therefore able to compare the two regions.

\section{Terminology}

One of the few peculiarities of inspecting the different perspectives involved in this scenario is the different terminology used when referring to the same subject matter.

Three particular ideas were given different terms according to an individual's ethnic background.

The first terminologically different concept is the idea of "Occupation" versus "Inclusion" in regards to the Soviet Union. Estonians believe that their country was wrongfully occupied from 1941 onward by the Soviet Union. Other member countries of the European Union along with the United States were some of the first to recognize Estonian independence in 1991, however not all of them recognize the time period as an "occupation." Russia and the Russian minority of Estonia and elsewhere often refute the idea that this era can be considered an "occupation" and that rather the country was "included" in the Soviet Union. This difference in interpreting the past not only causes communication problems and tension, but also in regards to the schools' curriculum, creates challenges for certain teachers.

The second concept that should be noted is the difference between the Estonian idea that the ethnically Russian inhabitants of Estonia are "immigrants" rather than a "national minority."

\footnotetext{
${ }^{69}$ Appendix C
} 
This is where the problem of citizenship erupts again. Unless one's family has lived in Estonia since before 1941 or unless one was born after 1991, people who do not fit these criteria hold immigrant status until they can pass an Estonian language exam in order to gain citizenship. If these same people - some of whom might have lived in Estonian territory for decades and might have been born and raised on Estonian soil, just not at the right time - were given the status of "national minority," citizenship would not be such a problem. Then this starts another debate, that if they were considered a national minority, considering they make up one fourth of the population, shouldn't Russian be added as a second official language?

The third and final terminological debate that will be examined in this section is the idea of "Integration" versus "Assimilation" in the school system. Most of the people, ethnically Estonian and Russian alike, have commented that the concept of integration goes both ways. They say that to be integrated means that two or more cultures come together, adopting and sharing different aspects of their lives and histories to form a new coherent amalgamation with which they can both associate. It is evident in the Estonian educational policies that this is not the case. Russian is optional as a second language in Estonian schools, and occasionally it's not even offered, whereas different Estonian immersion programs are being implemented so as to help ethnically Russian students fuse more easily with Estonian society. Some members of the ethnically Russian population find this to be more of a process of "assimilation" rather than "integration." At best, the objective is more involvement in the broader society, but at worst it could be seen as a means to strip ethnically Russian people of part of their identities. 


\section{CHAPTER SIX: Analysis}

Until now, the main methods of quantifying successes and failures in the integration of Russian-speaking minorities into the greater Estonian society have relied primarily on the statistics of language acquisition. Although this is an essential factor in the integration process, the idea that a greater knowledge of Estonian language has a direct correlation to providing the language acquirer with a greater inclination towards being a willing and socially aware citizen of Estonia. As the old adage states, "just because a cat has kittens in an oven does not make them muffins," and with the Integration Strategy implemented by the Estonian government, the expectations for the students of these programs to quickly become active members of the Estonian civil society is just unrealistic. There needs to be a bit more give and a bit less take on the side of the Estonian government. Language is only one among many different inter-related facets of any society, and focusing so intently on it as a means of determining success or failure of the integration process, can create a misperception of the actual issue This is not to say that the eventual goals of the government-mandated programs and strategies for a more integrated and cohesive society are not well intentioned, or that great strides towards these goals have not been made with the compliance with these new reforms of schools, teachers and students. Unfortunately for the Estonian society, and for the Russian-speaking minority in particular, the "multicultural" intentions are not always translated in the practical application of the government-instituted reforms to education.

So here we must ask how the Estonian society can progress from this point. Albert Einstein is famously quoted for saying, "The definition of insanity is doing the same thing over and over again and expecting different results." Of course, there is also the old proverb saying, "If you fall off a horse, get right back on." If what the Estonian government hopes to produce out of the educational reform set in place by the Integration Strategies of 2000 and 2008 is, in fact language acquisition and not social cohesion, then the goal should be met with time and reinforcement. However, if the Estonian government truly wants to build a more cohesive society, the efforts of the Russian-language schools and the attempts of the language immersion schools should be matched by their Estonian counterparts. In investigating which of these iconic phrases is more applicable to the situation in Estonia, I will be focusing on the concept of 
language immersion and the implementation of different types over the course of the decade. By noting the changes made in the execution of these policies and the reactions from the public sphere in media articles and personal interviews, I will be able to analyze the general successes and failures of the reform programs.

In this chapter, I will be addressing this issue along with some of the other obstacles that Estonia faces in the path towards social cohesion and the role that educational reform plays in the integration process. By focusing on the willingness to reform by both the citizens (the parents and the pupils) as well as the institutions (the schools), a better understanding can be gathered of how far the country has progressed towards the goal of social cohesion. The three different case studies will be analyzed as to the conduciveness of the environment for progress towards social cohesion and the effectiveness of the integration program in respect to the goals set by the state. This study's initial intention behind the case studies was to create comparison and stir debate as to which has had the most success in the context of multiculturalism, but during the analytical process, it appeared that no conclusive evaluation could be made because the disparities are irreducible. Instead, each case study will be appraised based upon its school's ability to prove the existence of Berry's four pre-conditions of multiculturalism, which are (for recollection purposes): "a widespread acceptance of the value to a society of cultural diversity, relatively low levels of prejudice, positive mutual attitudes, and a sense of attachment or identification with the larger society., 70

Evaluations of the case studies alone do not provide enough evidence for justifying or criticizing the existence of these governmental integration programs. Later in the chapter, different perspectives gathered from the general population of Estonia will provide another facet to the analysis. Randomly surveyed citizens were asked their opinions regarding the educational reforms and their own personal experiences with the Estonian educational system. These, too, will be examined according to Berry's model of multiculturalism.

${ }^{70}$ Berry, 11 . 


\section{Case Studies According to Berry}

Each school will be evaluated based upon their ability to subscribe to Berry's preconditions for multiculturalism according to the interviews conducted during the school visits, the school's standardized testing scores that were done by the Estonian government, and the availability of immersion programs at the school or opportunities for multicultural enrichment through scholastic programs. Again Berry's pre-conditions are:

a) the widespread acceptance of the value to a society of cultural diversity (i.e. the presence of a positive "multicultural ideology");

b) relatively low levels of prejudice (i.e. minimal ethnocentrism, racism, and discrimination);

c) positive mutual attitudes among cultural groups (i.e. no specific intergroup hatreds);

d) a sense of attachment to, or identification with, the larger society by all groups. ${ }^{71}$

Berry's pre-conditions for multiculturalism are probably most appropriate for evaluating the school in Tallinn. With half of the population speaking Russian as their maternal language, the environment is impressively diverse culturally speaking, which provides for a great deal of resources, particularly for staff and materials. While at the school the researcher noticed that the faculty and students were welcoming and generally helpful, but at the same time they were not championing the ways their school was diversifying the atmosphere. Not that any of them were particularly opposed to the sentiments that multiculturalism entails, but they might not be able to see the benefits because they are so exposed to them all the time. Therefore, in regards to the first pre-condition of "widespread acceptance of the value to a society of cultural diversity" in Tallinn, this researcher is hesitant to say that it has been attained.

Narva is a different story completely. The resources in northeastern Estonia are nowhere near that of the capital, and yet the parents petitioned the school for the implementation of a language immersion classroom. This not only shows that the school at the focus of the case study in Narva has met the pre-condition for widespread acceptance of the value to a society of

${ }^{71}$ Berry, 11. and R. Kalin \& J.W. Berry, "Ethnic and Civic Self-Identity in Canada," Canadian Ethnic Studies. 
cultural diversity, but the community surrounding the school is enthusiastically supporting the idea.

The case study in Tartu seems to provide for the best of both worlds, having a vast array of resources available due to the University of Tartu within the city limits and also an active community supporting the school's endeavors. The students, teachers and especially the director are aware of the merit that multiculturalism can provide for individuals, schools and whole communities.

The topic of prejudice is hard to quantify in any of the case studies. It seems impossible to think that any of the school's staff would make negative comments or blindly stereotype and discriminate against a person based on that person's native tongue, ethnicity, religion or any other reason. The students of the school in Tartu were more open during the conversation about community, and mentioned that occasionally they do not feel safe speaking Russian in certain neighborhoods because they have heard stories about crimes committed there against Russophones. Also, it should be taken into consideration that just a few years prior to this study the city of Tallinn had been under a strict curfew due to the crimes committed in relation to the events of the Bronze Soldier Statue. In general, however, Berry's idea is that there should be "relatively low levels of prejudice," and in 2011, all three surveyed cases seemed to pass this pre-condition.

The fourth and final precondition Berry assigns, "a sense of attachment to, or identification with, the larger society by all groups," is inconsistent among the three cases. In Tallinn it was evident that the students and teachers personally disagreed to an extent- the students identifying wholly as Russian and the teachers identifying as more Estonian or European. This could be a matter of personality or generation, but in general, the case does not give a unified response, so Tallinn does not achieve this precondition in the opinion of the researcher.

That the students in Narva can be exposed to a culture through the language immersion program other than their native Russian, which surrounds them daily, is promising for how the young pupils will someday identify. The director noted that it was far too early for the students 
to self-identify as predominantly Russian, Estonian or European, as they had entered the earlyimmersion class just a few years ago. In this regard, this precondition cannot be applied to Narva, but this has a greater potential to change in years to come.

And finally, this researcher believes that the students and the staff of the school in Tartu have reached a unique place in self-identification. The students spoke of plans to attend Estonian or European universities. During the school assembly that the staff and students invited the researcher to attend, the students expressed themselves through song and dance of various different cultures and styles. It is more than safe to assume that they have an attachment to Estonia, in more ways than territorially, as well as identification with the larger European community.

All in all, the case study that achieved three out of the four preconditions (that could be evaluated based solely on the data gathered during the case studies) was the school in Tartu. It is possible that in a few years time, a re-evaluation of the Narva case study will prove that that school will have attained the same readiness for multiculturalism, as defined by Berry. This is not, however, meant to disparage the school that is the focus of the case study of Tallinn. This simply proves that the language immersion programs do more than just advance the students' knowledge of Estonian language. These programs also promote multiculturalism and in the same respect, a cohesive Estonian society.

The pre-condition that was not mentioned above, the third pre-condition of "positive mutual attitudes among cultural groups," has been determined to be very difficult in application to the scholastic settings that the other pre-conditions have been applied to. Solely analyzing this pre-condition in a static environment would be unwise, as it implies reciprocation. This being said, the school environments can be combined with the interview responses and other information that was gathered, and perhaps this third pre-condition can be analyzed on a panEstonian scale. Each of the schools was predominantly Russian-speaking, and all sentiments about their Estonian counterparts seemed relatively positive. The interviews done with Estonian nationals are not always so positive, in fact, some persons even flatly say, "I do not like Russians." But others are quick to point out that it is a "delicate issue" and "it is not so black and 
white. ${ }^{72}$ Other statistics are available from studies in previous years, one in particular that might be applied to the idea of positive mutual attitudes among cultural groups can be seen in Appendix D. The representation of Mutual Inter-Ethnic Identification shows that Non-Estonians mostly identify with groups termed, "Russians" or "the Russian-speaking population of Estonia," whereas, the Estonians only vaguely can identify with such groups. The same phenomenon can be seen in the Non-Estonians ability to identify with the group termed, "Estonian." Not being able to identify with persons of other ethnicities is not necessarily a sign of negative mutual inter-ethnic attitudes, but neither is it necessarily positive. From this graph we can simply infer that there is a distance felt in respect to Non-Estonians versus Estonians.

\section{Interview Peculiarities}

It is interesting to notice the trends that happen among the generational lines, ethnic lines and across the different categories of persons in regards to the interviewee responses. Responses from people of the same ethnicity can be completely opposing across generations, but intergenerational responses across ethnicities will be quite similar. For example: a young Estonian student from a rural area does not find any fault in the lack of communication between the ethnicities, however, an Estonian former student from Tallinn acknowledges that there is not a very good mutual understanding between the ethnicities. Another interviewee from the same age range also gave a similar opinion, however this interviewee is a Russophone from Tallinn.

This anomaly is only present in the generations older than 18. Perhaps the students who are currently involved in the educational system are either too close to the issue to be objective, or too far removed from the situation to give useful data. Another question that comes to mind is whether or not these attitudes will change with time, once the current students reach the collegiate atmosphere, and once the former students reach the workforce. Such data would be an intriguing contribution to the field of study.

\section{Common Problems Across the Board}

Two graphs have been created to demonstrate the differences between the number of

${ }^{72}$ Interviews from Student 5 and Former Student 5, respectively—Appendix C. 
students who participate in Estonian language-of-instruction schools by county ${ }^{73}$ versus the number of students who participate in Russian language-of-instruction schools by county. Before analyzing these graphs, it should be noted that in 2007, surveys gathered data showing that $81 \%$ of schools in Estonia use Estonian as the language of instruction, and only $14 \%$ use Russian, while the other $4 \%$ are bilingual ${ }^{74}$.

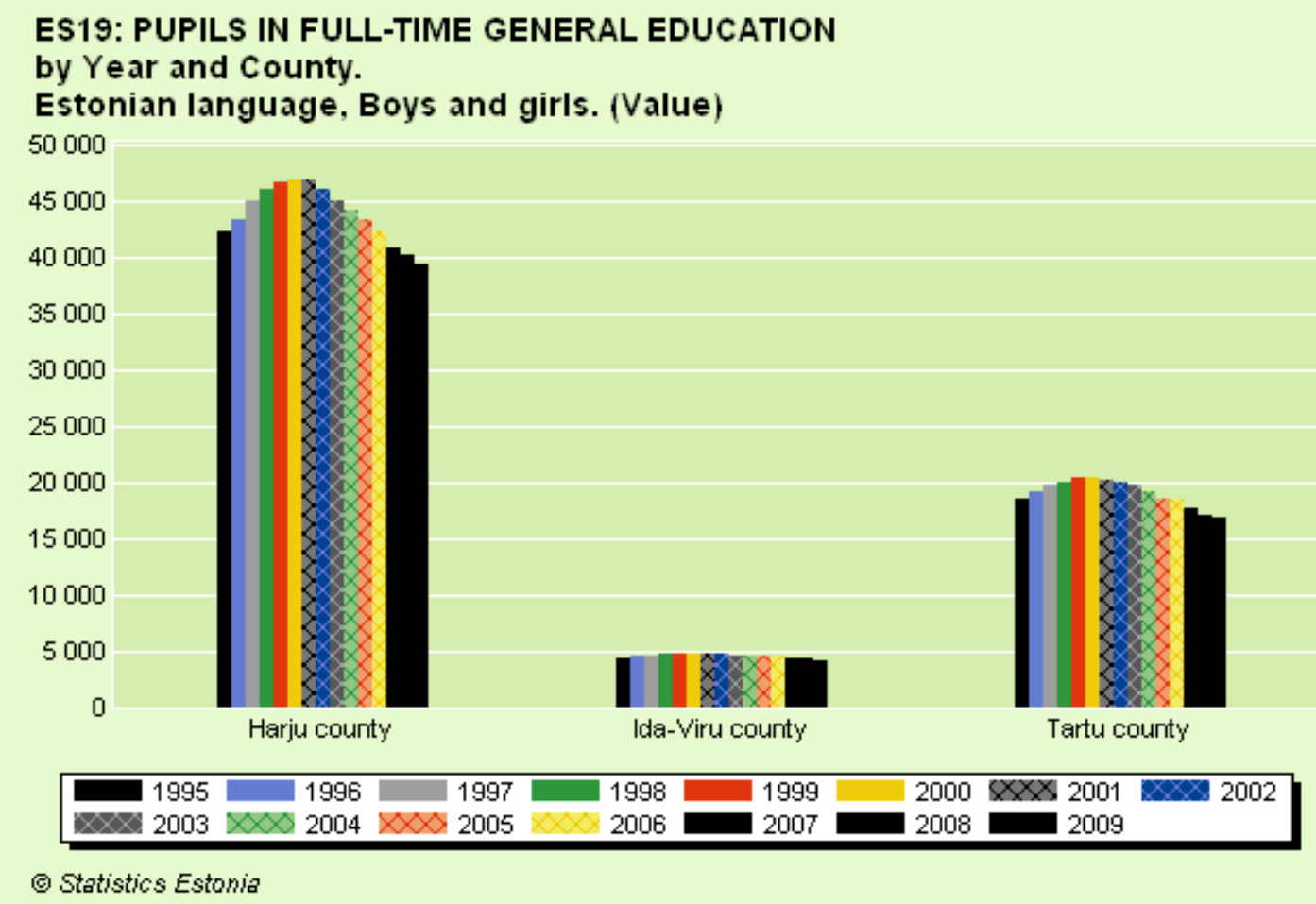

Figure 11

The first graph shows the number of pupils in Estonian-based schools in the same counties that make up the focus of the case studies. The second graph shows the same information, except in Russian-based schools. It is clear that the total number of pupils is dwindling - but what cannot be seen in these graphs is the effect that the numbers have in actuality.

\footnotetext{
${ }^{73}$ The three counties surveyed correspond with the locations of the schools in the case studies.

${ }^{74}$ Data gathered from www.stat.ee.
} 


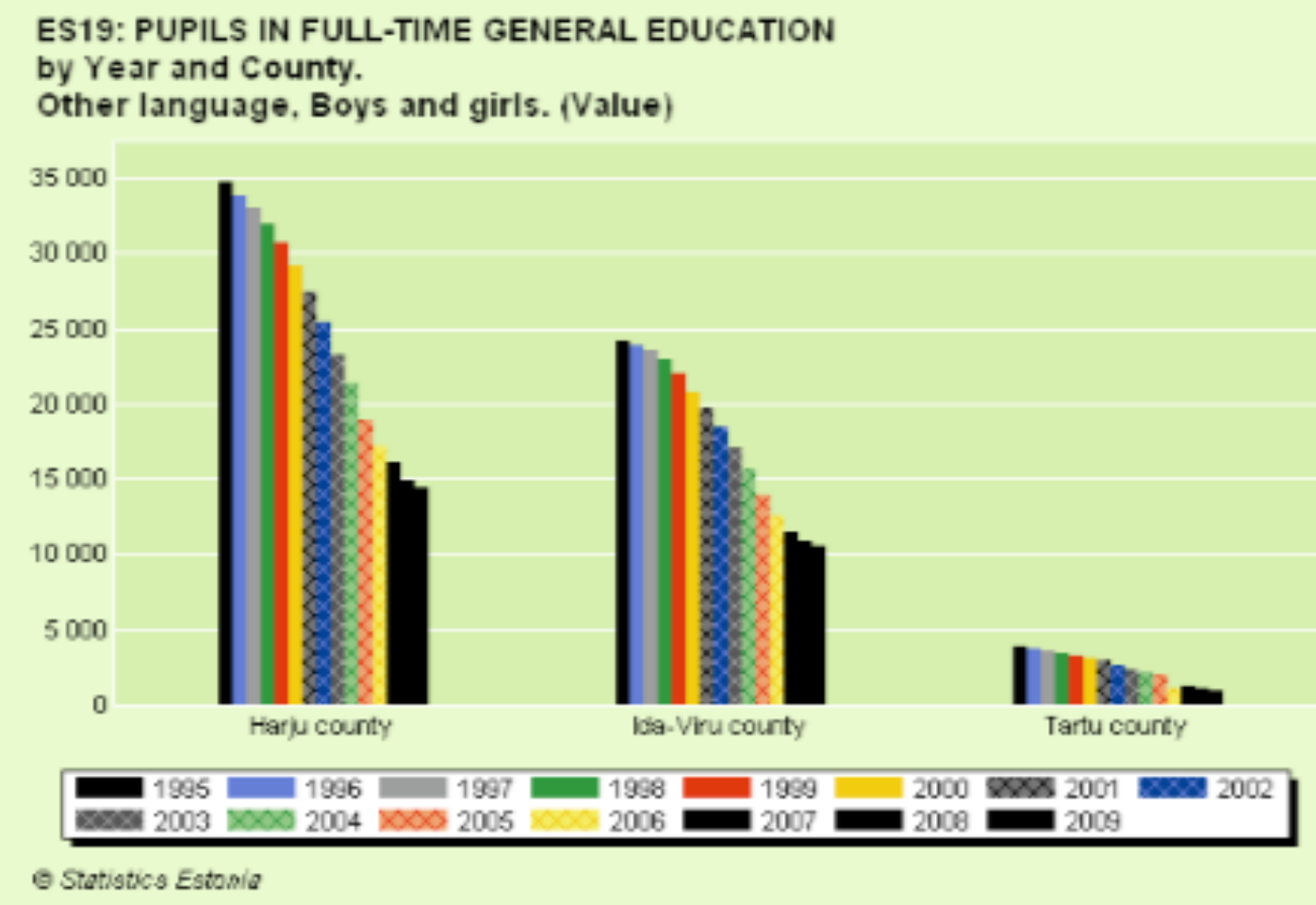

Figure 12

Without an adequate number of pupils, many Russian-medium schools are being forced to close. Consolidation has occurred in some situations, other times Russian-speaking students will transfer to an Estonian-medium school or a language immersion program if it is available in the area. This has had a positive affect on language immersion schools, as can be seen in their numbers. In 2000, the program started out with 134 students in 4 different schools with 5 separate classrooms. This number has grown steadily over the years and in 2008, the Integration Foundation recorded 4566 pupils across 31 kindergartens, 16 elementary schools, and 21 middle schools. 


\section{CONCLUSION}

So where is the problem in enforcing language requirements for citizenship and matriculation? Everyone interviewed seems to understand the benefit of being bilingual and of having a multicultural society. Every school visited comprehends the need for their students to learn Estonian language and to integrate into the greater Estonian society. What is holding the Estonian society back from the social cohesion that the government and seemingly the people have been longing for over a decade?

In light of the data gathered from this thesis, the problem lies both in the past and in the present. Twenty years ago, Estonia as it is today, an independent and democratic state, a member of the United Nations and the European Union, did not exist. The scars of Soviet past have not entirely dissipated from the minds of the generations who lived during its reign, and the memories of the decades spent under the totalitarian rule of the Soviet Union are not something that can be changed by passing legislation. The Estonian government's ability to create a cohesive society is only possible as long as it is adopted on a personal level by individuals and communities who find developing a multicultural society a priority. Estonia is unique, and the

diversity that can be found within its boundaries should be seen as an asset to the society as a whole.

The whole issue of education reform is dependent on so many different variables. Static thinking does not lead to progress, and promoting conformity does not bring about change. Statistics have their place in the evaluation of programs and institutions, but the idea of the "carrot and the stick" is not always successful in creating good results. Schools have different resources allotted to them, often not by any discretion of the government. By penalizing schools, which have fewer resources, i.e. community involvement, experienced teachers, funding, etc., the problems can be prolonged if not worsened. Also, by having standardized expectations of schools, despite their resources, or lack thereof, the ends do not justify the means. Especially if those means, i.e. integration programs, have not exactly proven to be correlated to the ends in question, i.e. social cohesion. 
So is there hope for the future? The coming years are crucial to the end goal of social cohesion in Estonia. The first groups of students who have participated in the beginning phases of the language immersion projects will be graduating and moving on to higher education. If these students, who were the guinea pigs of their generation, set good examples of the forthcoming achievements of language immersion graduates, the availability of these kinds of programs will be much more desirable to the public. Once the public gets enthusiastic about language immersion and its benefits, the schools that have not yet participated will begin to take more interest and strive to achieve the same status.

As in the classic formulation, the few impact the many. The people who organize the language immersion program are trailblazers for Estonia's educational reform. Unconventional and open-minded, the women and men who have initiated these types of learning environments, whether they be language instructors, school directors, parents, or the Minister of Education himself, have done a great service to the Estonian society with the language immersion schools, from what this researcher has witnessed. This is all done in a setting that is voluntary, and therefore has no impact on the fear of losing one's cultural heritage. For the most part, what these schools are doing is not only a service because of the bilingualism that it instills in its students, but because of the open environment it promotes. Of course, language is one of the more evident effects of a language immersion school, but what really occurs is something that is hard to calculate.

Teachers who are trained specifically to be in a bilingual classroom provide good role models. They become the embodiment of a success story, representatives, perhaps from the same linguistic background as the student, who have acquired a skill and now employ it for the benefit of society. Or perhaps the teachers can provide an example of a relatable person from a different ethnicity. Not only will students pick up on these traits, but also, as it has been the case for centuries, teachers really do have a great impact on their students lives long after they leave the classroom, as Socrates was a mentor to Plato and Plato was a mentor to Aristotle. In this same way, the students of language immersion programs can become role models for the rest of the Estonian society. They will become spokespersons for the benefits of bilingualism, and the people who fear losing their cultural heritage or identity will be comforted by the images of the successful students, and their achievements in society. 
In the near future, if language immersion schools continue to grow with the popularity they have in the past decade, the linguistic barrier that faces the older generations will have all but vanished for the younger generations. Along with that, the marginalization of the Russianspeaking communities of Estonia will decrease in all aspects of life, and the goal of social cohesion will become more and more of a reality. Although, this may seem idealistic, one image that the researcher came across on one school visit gives the impression that perhaps the idea of integration will come easier with each new generation, or even each new class. The image was a drawing made by a young pupil at the school in Tartu. It shows three birds, barn swallows to be specific, which is the national bird of Estonia, and they were peculiarly hued. One was colored in the fashion of the Estonian flag, one was colored in the fashion of the flag of the Russian Federation and the last was adorned with 12 five-pointed stars like the flag of the European Union. The symbolism of respect and unity through diversity that this young person showed in this piece of artwork was inspiring to say the least. One can only hope that Estonia allows the younger generations, like the student-artist, to motivate the Estonian people and pioneer the next innovative waves of integration for the educational system and the society as a whole. 


\section{Bibliography}

Primary sources:

Belova, Svetlana. Personal INTERVIEW. Tallinn, Dec. 15, 2010.

Citizen A. Personal INTERVIEW. Tartu, April 8, 2010.

Citizen B. Personal INTERVIEW. Tartu, April 8, 2010.

Citizen C. E-mail INTERVIEW. November 11, 2010.

Citizen D. Personal INTERVIEW. Tartu, December 13, 2010.

Director A. Personal INTERVIEW. Tartu, May 7, 2010.

Director B. Personal INTERVIEW. Narva, May 28, 2010.

Director C. Personal INTERVIEW. Tallinn, May 31, 2010.

Former Student 1. E-mail INTERVIEW. October 10, 2010.

Former Student 2. E-mail INTERVIEW. October 10, 2010.

Former Student 3. Personal INTERVIEW. Tartu, November 30, 2010.

Former Student 4. Personal INTERVIEW. Tartu, December 1, 2010.

Former Student 5. Personal INTERVIEW. Tartu, December 1, 2010.

Former Student 6. E-mail INTERVIEW. Tartu, December 13, 2010.

“Immigrant Population in Estonia." Statistics Estonia: Tallinn, 2009.

Integration Foundation. "Estonian Integration Strategy 2008-2013" (Unofficial Translation) Ministry of Population and Ethnic Affairs: Tallinn, 2007.

"Language Education Policy Profile: ESTONIA" Language Education Policy in Changing Society: Shaping the Future. Council of Europe (2010) www.coe.int/lang

Kebbinau, Maire. Personal INTERVIEW. Tallinn, Dec. 15, 2010.

Piirsalu, Karin. Personal INTERVIEW. Tallinn, Dec. 15, 2010. 
State Integration Programme 2000-2007. “Mid-term Appraisal Report” Euroopa Liit, 2006.

State Integration Programme 2008-2013. "Final Report on Needs and Feasibility Research." (Unofficial Translation). Ministry of Finance of the Republic of Estonia: Tartu, 2008.

Student 1. Personal INTERVIEW. Tartu, May 7, 2010.

Student 2. Personal INTERVIEW. Tartu, May 7, 2010.

Student 3. Personal INTERVIEW. Tallinn, May 31, 2010.

Student 4. Personal INTERVIEW. Tallinn, May 31, 2010.

Student 5. E-mail INTERVIEW. December 4, 2010.

Student 6. E-mail INTERVIEW. December 5, 2010.

Teacher 1. Personal INTERVIEW. Narva, May 28, 2010.

Teacher 2. Personal INTERVIEW. Tallinn, May 31, 2010.

Teacher 3. Personal INTERVIEW. Tallinn, May 31, 2010.

Secondary Sources:

Berry, John. "Immigration, Adaptation, Acculturation," Applied Psychology and International Review. 46-1, 1997: 5-68.

Berry, John, Kruusvall, Juri and Vetik, Raivo. "The Strategies of Inter-Ethnic Adaptation in Estonian Russians," Studies of Transitional States and Societies, 1-1 (2009) 3-24.

Evans, G. "Ethnic Schism and the Consolidation of Post-Communist Democracy: the case of Estonia." Communist and Post-Communist Studies. 31-1, 1998: 57-74.

Haav, Karel. "The Estonian Educational forum: main stake-holders and models of decision making." The $12^{\text {th }}$ NISPAcee Annual Conference. (Working Group on PoliticoAdministrative Relations)Vilnius, 2004: 1-7.

Hallik, K. (ed.) "Monitoring Process 2002" Institute of International and Social Studies and the Integration Foundation: Tallinn, 2002.

Hogan-Brun, Gabrielle. "Language-in-education across the Baltics: policies, practices and challenges" Comparative Education (43:4) Routledge: London, 2007: 553-570. 
Kalmus, Veronika. "Is Interethnic Integration Possible in Estonia? Ethno-Political Discourse of Two Ethnic Groups," Discourse and Society (14) Sage Publishers: London, 2003: 667697.

Kalmus, Veronika and Marja Pavelson. "Schools in Estonia as Institutional Actors and as a Field of Socialization." From Lauristin, Marju and Heidmets, Mati. (eds.)"The Challenge of the Russian Minority: Emerging Multicultural Democracy in Estonia." Tartu University Press, 2002: 227-236.

Korts, Kulliki. "Inter Ethnic Attitudes and Contact between Ethnic Groups in Estonia" Journal of Baltic Studies (40:1) Routledge: London, 2009: 121-137.

Lapping, Mark B. "Educaton in a Restoration Democracy: The Case of Estonia" Citizenship, Social and Economics Education. 6-2, 2004: 101-115.

Laitin, David. Identity in Formation: The Russian-speaking Populations in the Near Abroad, Cornell University Press, 1998.

Laitin, David. "Three Models of Integration and the Estonian/Russian Reality." Journal of Baltic Studies. 34-2. 2003: 197-222.

Lauristin, M and Vetik, R. (eds.) “Monitoring Process 2000” Institute of International and Social Studies and the Integration Foundation: Tallinn, 2000.

Mertlesmann, O. and Rahi-Tamm, A. "Soviet Mass Violence in Estonia Revisited," Journal of Genocide Research. 11-2-3. 2009: 307-322.

Misinaus, R and Taagepera, R. The Baltic States: Years of Dependence-1940-1990. Uni. California Press, 1993.

Pavelson, M., Proos, I., Pettai, I., Kruusvall, J., Hallik, K., and Vetik, R. (eds.) "Monitoring Process 2005" Institute of International and Social Studies and the Integration Foundation: Tallinn, 2005.

Protassova, Ekaterina. "Latvian Bilingual Education: towards a new approach" International Education.13:4 Carfax Publishing: Oxfordshire, 2002: 439-449.

Raun, Toivo. Estonia and the Estonians: Updated Second Edition, Hoover Institution Press, 2002.

Rex, John. "Multiculturalism and Political Integration in the Modern Nation-state." Revista HMiC , 3. 2005: 249-261.

Valdmaa, Sulev. "Developing civic education in Estonia" Curriculum Change and Social Inclusion: Perspectives from the Baltic and Scandinavian countries. International Bureau of Education: Lithuania., 2001: 71-79. 
Vetik, Raivo. "Democratic Multiculturalism: A New Model of National Integration." Aland Islands Peace Institute, 2000. 


\section{APPENDIX A}

\section{Schedule of Interviews-}

April 8, 2010-Interview with Citizens A and B

May 7, 2010 — Visit to School A, Tartu—-Interview with Director A, Students 1 and 2

May 28, 2010 — Visit to School B, Narva-Interview with Director B, Teacher 1

May 31, 2010 — Visit to School C - Interview with Director C, Teachers 2 and 3, Students 3 \& 4

October 10, 2010-E-mail, Former Students 1 and 2

November 11, 2010-E-mail, Citizen C

November 30, 2010-Former Student 3

December 1, 2010—Former Students 4 and 5

December 4, 2010-Student 5

December 5, 2010-Student 6

December 13, 2010_Citizen D, Tartu; Former Student 6

December 15, 2010 - Interview at Migration Foundation, Tallinn 


\title{
Appendix B
}

\author{
INTERVIEW, INTEGRATION FOUNDATION (www.meis.ee), TALLINN
}

DECEMBER 15, 2010

-Svetlana Belova, Coordinator of Language Immersion in kindergarten

-Maire Kebbinau, Coordinator of Language Immersion Schools

-Karin Piirsalu, Coordinator of Language Learning Program Development and Implementation

Interviewer: How is the Integration Foundation involved with school integration in Estonia? How much?

SB: The Ministry of Ed. \& Research is financing portions - the language immersion primarily. In 2000 the language immersion center started. There were 4 schools and 5 different classes for language immersion - one school had 2 classes. 2002 the kindergarten level was started. It is total language immersion. From the 1st form, all subjects taught in Estonian. For 5 years, (2 years before school) all studies are in Estonian. In 2002 the late language immersion program "projects" were started. The early- and late-immersion programs were financed early on by the Canadian government and the kindergarten immersion was financed by northern countriesFinnish specialists.

MK: There are criteria for the schools to join this program. It is voluntary. Criteria includes things for the teachers, school development programs, the parents, materials, etc.

KP: First we were thinking about developing materials for all of the children. We have books for kindergarten, "Big books" that were specially developed for us. They are open for everyone. We get feedback that they are very good for everyone.

\section{I: What is your opinion on the progress of the state-initiated integration strategy (in respect to education)?}


KP: Children were observed in the beginning, and they found that they were all the same. Comparisons made at the third grade (state level tests). The results for the children from immersion classes were very good. In some aspects a bit better than children at traditional Russian schools. The Estonian language skils were not as good as the Estonian-based, but nature, science, and math subjects all tested at the same level.

SB: The parents and the materials are really important. The immersion courses stress human values in everyday life. We tried to avoid stereotypes, using all cultures in the materials (i.e Russian names). The writers of the material are also teachers, and many improvements have been made. They weren't even in color the first year we were testing them out.

MK: I think we have reached a level where the children can decide how to integrate and do somehting about their own integration. They have more possibilities to go to university or European universities. They have courage, a curiosity for knowledge. Some of the students now dream of being language immersion teachers. They are really good communicators.

SB: We now have 34 schools, 34 kindergartens, almost 4000 pupils. Now in the national curriculum for kindergartens they have two programs. Total - which is 5 years, allowing for the students to start speaking and learning in their mother tongue. There is also partial - that is 3 years, with one Estonian teacher and one Russian teacher. The bilingual atmosphere allows them to grow in both languages. The directors saw problems with the programs before and changed it. Teachers must have good ability to cooperate and blend together, or else it doesn't work so well. The parents seem very happy too- they get to choose the schooling.

\section{I: What still needs to be accomplished? How does the IF help with the progress?}

MK: Maybe teacher training programs should be improved at the university level. We are doing Content Language Integrated Learning (CLIL). This means that the students are not just learning Estonian, they are learing in Estonian.

KP: WE have new curriculum for schools. This makes more work with secondary schools in regard to subject teaching. The teachers need to integrate language and subject knowledge. They 
don't want to be language teachers, and maybe they don't understand it completely, but they must be done together.

SB: Some don't want to be language immersion teachers. But this is more effective at gumnaasium level and for immigrants too. This isn't a pure program, though.

\section{I: What are some common complaints or problems that you hear about-from directors? From teachers? From students? From parents? From citizens in general?}

SB: That there aren't enough teachers. They need more competence from the university level.

MK: Different training courses from different teachers and universities (University of Tartu and Narva College are very different).

KP: Some of the parents need to be counseled on how to "let it be." Each child is different and will learn at their own pace. A child needs to be given space so that they can learn peacefully in their own time. Parents' Association goes visiting different places (schools, countries) and sharing their experiences.

SB: The program is voluntary. And we have grown from 4 schools to 34 schools. The interest is obviously there. 50 percent of Russian language schools are involved in some kind of language immersion program. The teachers' roles are very important. Thye do a lot of work-they teach a language and alto get more knowledge about the subjects. It takes a lot of time and effort.

MK: The Ministry of Ed. \& Research supports language immersion teachers with special financing. Its not big, but it is some kind of motivation. It helps improve the classroom. Immersion teachers also get a $\%$ increase in salary (up to $20 \%$--in Narva), it really depends on the region.

\section{I: What do you think the Estonian society believes about this program? Are there some common misconceptions?}

KP: Myths are that immersion is only for talented children or only for children with mental disabilities. The idea is that they play a lot. 
SB: Some people think that the children don't know subjects in their mother tongue.

KP: One first grade parent in Tallinn tok their child from the classroom because it was too happy. This is strange for parents - the idea that school must be difficult and that you can't learn in a place where there is play. They can't understand that learning can be fun. Look at delfi.ee or delphi.ru - there are comments and discussions in Russian from the parents.

MK: Immersion is a soft or human way to learn a new language for children with Russian as a mother tongue. In the Estonian-based schools, they have no time to wait for you. In the immersion class, time is given to learn, everything is thought through, not too much pressure is placed on the child, and it preserves the mother tongue.

SB: Russian language is still important. Mother tongue and culture are a top priority.

\section{I: Has society received this program differently in different areas? Which have been the most/least successful?}

SB: This program is received the same everywhere. All are given recommendation for subjects which are better to be taught in Estonian.

KP: There are very motivated parents, teachers, and students in places where they don't have language environments outside of the schools. Tallinn and Tartu have more language environments available to them. But the language test results are the same.

MK: As far as regional differences go, we are warmly welcomed in the Eastern part, where Russian language is most prevalent. Other areas are more reserved. This could be a cultural neutrality.

SB: You can't say one is better than an other. It really depends on the school and what kind of teachers they have.

\section{I: What kinds of specific integration programs are the most/least successful in your opinions?}


KP: Comparing early- and late-: early-immersion is more successful for students. It comes more naturally, there is more open communication. Also to support these children later we need developed secondary school programs. If Russian dominates in primary school, then Estonian language will suffer. Most students spend their outside activities in Russian language environments. Late-immersion requires that the children be very motivated. They have a lot of things to juggle.

\section{I: What is the "end result?" What can we expect to see change in the Estonian society in the future due to these policies and programs?}

KP: Happy citizens in Estonia. Language will cease to be an issue at political levels. At all levels, really. Hopefully, Estonian-speaking citizens will be more motivated to speak Russian.

SB: Of course, they would be able to feel free in both languages and cultures, be more accepting of people from other cultures.

MK: Immersion methods would also be good to start in Estonian schools - new methods, new models. Autocratic vs. Democratic.

SB: Somedays Russian speaking people feel ashamed to speak their national language. The new generation will fell better, they will be proud to be Estonian and Russian.

KP: The future is multicultural. So we need to be prepared, and the language immersion program is a way to be prepared at te school level. For teachers to feel secure when they have other immigrants - it doesn't matter what language, if it is Spanish, English, etc.

MK: We can see more and more interest from teachers at common schools. Tallinn English College started teaching specifically CLIL courses.

\section{I: How much of an influence do you think that school integration has on the larger society?}

KP: If parents can see improvement of their children at home (they are happy and open-minded) I think that this is positive feedback to the wider society. 
SB: Kindergarten started with one immersion group. It was very colorful and interactive. The teachers were very influential and motivated. They were determined to set a routine and the rest of the school saw this and adapted to it gradually. Other schools in the area started to improve themselves to compete. This is just one example.

KP: It is very important to see the immersion students going to Estonian universities and European universities — getting degrees and feeling more secure. This would have a very positive impact on society. 


\section{APPENDIX C}

Citizens A and B

April 8, 2010,3PM-Tartu

Interviewer : So what is your relation to the integration process and educational reform in Estonia?

Citizen 1: Well, we have a business. It's a non-profit youth organization that is aimed at filling the emptiness from formal education. We deal with culture and communication. But we are not trying to "build a bridge" more we are trying to raise active citizens. Integration comes naturally, we actually try to avoid the word - the definition is based in division. Especially in Estonia, integration is more "assimilation." The groups we work with are mostly 15-18-age range-they are difficult, they don't know what they want. Then sometimes we deal with 18-30, and they already have some direction and values. As for me, my B.A. is in Philosophy and Culture, and I am working on my M.A, but I have had a lot of experience outside of this field. We do a lot of volunteer work internationally — sending volunteers, finding places for them, preparing the trip before they go, appropriate projects and budgets. My job is a part of my life, there is really no distinction between public and private life.

\section{I: Why did you create your business?}

$\mathrm{C} 1$ : The organization is not aimed at Russians, but we just know the problems from this perspective. Our Estonian language is not perfect, but we manage. We saw a need, and we want to help support people who have the motivation to build a community. We don't defend those people who are not trying to be involved, but we are trying to give opportunities to young people. They need chances to develop themselves, to establish self-esteem. They seem to be lost.

\section{I: Why do you think they are lost?}


C1: The polls and surveys about citizenship don't work. They don't feel like they don't have a motherland. It's a big mistake by the politicians - the youth are experiencing this phenomenon, like their identity was taken from them.

Citizen 2: The alien passports allows them to live and work and study, but soon the opportunities will expire if they don't assimilate, the eligibility for citizenship is dependent on Estonian knowledge. It's strange, because sometimes I see people supporting Russian sporting teams in the Olympics and things.

$\mathrm{C} 1$ : The identity is Russian. For people that identify Estonian, I think it is because they don't have such language problems. NGOs try to group people, but the truth is that for Estonia to survive, we gave to do trade with Russia. It is an exploding market; it is almost like we don't have a choice.

C2: The national priorities are the youth who don't speak Estonian, unemployed youth, youth from rural areas, youth with fewer physical opportunities, etc. The Ministry of Education has EU funds to address this, and the institutions that they put in place are eager to fix the situation. They try not to blame each other, but to compromise and balance the communities. Arguments only lead to aggression without a solution.

$\mathrm{C} 1$ : Sometimes it looks like an artificial problem. But there are broken expectations, connections to the land that people don't think about. Estonia was independent from 1918-1940, but from 1940 to 1991 is a long time, too. Estonians maybe use the strategy of "the other."

\section{I: How was it for you in school? Did you experience a lot of the attempts at integration yourselves?}

C2: I did Semiotics and Culture, and my faculty was very flexible. I don't think that language should be such an obstacle. "Integration" sometimes sounds a lot like "extermination." After 20 years to still have this issue - what have they done? Adults, ok, that is different. But why are the youth unmotivated? They haven't been taught to take advantage of this bilingual situation. 
$\mathrm{C} 1$ : The third year of independence, I graduated university. Ida-Virumaa is isolated; teachers couldn't explain or didn't want to explain what was going on in the country. People tend to use the word "incorporated" in regard to the time of the Estonian Socialist Soviet Republic as opposed to "occupied." I may have had the best grades in Narva, but I had to learn everything again. I didn't feel welcome. But there were certain fields that you could study in RussianSlavic Philology, Mathematics, Medicine, and Semiotics.

C2: There was not much choice. Some exceptions to the rule would be going to Russia for a B.A. or Tallinn there is the possibility to study in Russian at a private university, I think. Journalism, maybe? But in this recession, that is a lot of money. It has a lot to do with politics, I think. People would translate their names to assimilate or gain power. The former mayor of Narva, for instance. Or CEOs at different companies. There is a stigma with being Russian.

\section{I: What are the most important aspects of this issue?}

C2: I feel connected with the Russian Federation and with the European Union. Russian in the sense of culture, literature, music, etc. But in behavior, social aspects, values, territory, I feel very European. I think that is not something that is recognized by Estonians who do not have Russian heritage. In Kohtla Jarve, our school was in the same building, depending on language learning - it was a special place. But even inside the school there was not so much cross communication.

C1: Language is not the issue in Tartu; it is identity. Tallinn has 50/50 of Estonians and Russophones. Sometimes you can go into a shop and start speaking Estonian and then only after a couple of sentences do you realize that the salesperson speaks Russian as their maternal tongue. It's almost funny. But the thing is, we can all live together-have a symbiosis. We can benefit from other cultures. 
Interview with Former Student 1-received via e-mail, Oct. 10, 2010

School: Tartu public

Year Graduated: 2005

Ethnicity: Russian

Interviewer: What can you tell me about growing up in Estonia during the transition from Soviet Union? I know you might not remember a whole lot, but maybe how things changed for you (if they did)?

Former Student 1: To be true, I was too small to remember or recognize anything significant. I was only 4 when the Soviet Union collapsed. Everything I know about the first transition years, I heard from my parents.

\section{I: Were there any major changes made while you were in school?}

FS1: First of all, the length of the study period changed - from 11 to 12 years. I can't say exactly whendid it happen, but I know that e.g. my mum and some friends older than me studied for 11 years, while me - already for 12. Textbooks changed gradually - from published and written in the SU to Estonians one. But actually, what is interesting and what was common only for schools where the language of study was Russian (at least I suppose so and it was a practice in my school) - together with textbooks written by Estonians or published in Estonia, we continued to use Soviet textbooks in some subjects. Not many, but still. I guess it was a kind of additionally readings (extracurricular) that teachers used just for her/his own choice, and it was common for

older teachers mainly. Probably, it could be explained by her/his former habits - she/he was used to some textbook and she/he taught students using that book or she/he liked that book or he/she thought that material there was presented more clearly/understandably/in a better way than in newer ones.

\section{I: Did the subject of "integration" come up often? How did people feel about it?}

FS1: As for me (personally), I began to notice this governmental policy only some years ago, probably 4-5 years ago. From this time, the subject of integration has been coming up more often. In 2007 there was a period of working out of the new integration strategy in Estonia (for the years 2008-2013 I think), so this topic was largely discussed in the media, there were made 
numerous surveys among population etc. of course I heard about integration before 2007 as well (e.g. new educational systems and methods in Russian-language schools in Estonia, meaning that teaching of some subjects was changed from Russian to Estonian. But me personally it didn't touch, because in my school these practices weren't adopted - in Tartu it was only one Russianlanguage school that adopted and tried this method. Probably, now it is much more common throughout Estonia).

How did people feel about it? What can I say... I was born in very "Estonian" part of the country (Southern Estonia), where most of the population is Estonian, and Russians are in minority. And in general, Russians living in Southern Estonia are more integrated, or adapted, and usually have less problems related to integration - e.g. for the most part, they speak Estonian (at least, some Estonian, of course the level is extremely different!), that's why they can communicate with Estonian people, have less problems with finding a job (at least, the language factor is not the primary obstacle). That's why people feel quite positive about integration, are open to it. I don't know may be I'm wrong about it and have false impression. Because me personally - I feel integrated, my family does the same, we don't have any difficulties related to the integration theme - that's why probably I pay attention more to the positive side of the process of integration.

\section{I: What do you remember about the curriculum at your high school (secondary school)? Were there any subjects that you felt were stressed more than others and why you think it was that way?}

FS1: As much as I remember, the curriculum was balanced.

\section{I: How involved were you in the clubs and different activities at your school?}

FS1: There was very restricted number of such activities in my school. There were some hobby circles like drawing- or chorus but they weren't of my interest. The same about sport circles - the choice of sport, and other out-of-school activities in general was very limited.

\section{I: Can you remember any teachers in particular and why are they so memorable?}


FS1: There are some teachers that are memorable for me from the positive side (first, teachers competent not only as a teacher, but interesting and broad-minded as a person; then some charismatic teachers - I remember how they were held in a true respect among the students). Some teachers remained in my memory from not so positive aspect (mainly, because of the biased approach they expressed towards particular students).

\section{I: How was the transition from secondary school to university? Do you feel like you were prepared enough? (Also, what faculty did you enter in university?)}

FS1: I studied Government and Politics (the Faculty of Social sciences).

The transition from secondary school to university was pretty smooth for me. The main fear for Russian speaking people (that have been studying and graduated from the Russian schools) is, of course, possible language barrier and other language-related difficulties (because high education in Estonia is mainly in Estonian; there are some private universities that offer English or even Russian-based education, but these are few). As I have already mentioned before, I was adapted to the language quite well; however, it wasn't enough because previous 12 years of school education were in Russian and all my friends were Russians as well. But I got used to Estonian with time; the main advantage that facilitated it in my case was the fact that the field of study I've chosen wasn't popular among Russians, meaning that almost all my course mates were Estonians and I was forced to speak only Estonian at university. That was very good in terms of improving my language skills of course :). Furthermore, I had very nice and understanding course mates who knew that I'm not a native speaker and helped me in the process of communication as much as they could (were tolerant, suggested some words that were yet unknown for me when we were talking etc.). That's why my transition to university and integration into Estonian community was so smooth.

In terms of preparation - no, I didn't feel that I was prepared sufficiently. But I supposed it already before I entered the university, that's why I was morally prepared for this challenge

\section{I: What big events do you remember from when you were younger--maybe just at the} community level--that involved communication between the different ethnicities of

\section{Estonia?}


FS1: The Song festival -traditional/national Estonian event. Also different annual sport events cross country skiing and cycle race. Definitely, there were some other events as well, but at the moment nothing special comes to my mind.

It is difficult to say whether the way the ethnicities communicate has changed or not. I guess it has. I hope it has become closer. However, we have to admit that there are some representatives from both ethnicities* in Estonia that just don't want to communicate with each other. Or they don't feel that it is necessary, or they have whatever reasons, I don't know. Such people or groups of people were, are and will remain in society

Both ethnicities* - I mean Russians and Estonians here. Of course, there are some other minorities as well, like Ukrainians or Belarusians, but the percentage is much smaller than that of Russians. That's why I categorize e.g. Ukrainians also as Russians.

\section{I: What do you think about the political representation in Estonia?}

FS1: If we are talking about ethnical representation, I think that there are still not enough Russian-speaking representatives in politics as it might be. Of course, with time the percentage is growing, however, the level of involvement might be higher. 
Interview with Former Student 2-received via e-mail, Oct. 10, 2010

School: Tallinn, public

Year Graduated: 2004

Ethnicity: Russian

Interviewer: What can you tell me about growing up in Estonia during the transition from Soviet Union? I know you might not remember a whole lot, but maybe how things changed for you (if they did)?

Former Student 2: It was like living in two different worlds - first you are born into Soviet Union and then suddenly we understood that we are a part of Europe. Most of my childhood was still spent in Soviet Union, even though I was just 5 when Estonia became independent, our mentalities stayed Soviet for a long time to go. It was funny to visit friends and all of us had the same type of furniture, cutlery, plates, carpets, etc. We all liked all the small things that suddenly were imported from the West - lollipops, chewing gums, chips, etc. Children are usually not very politicized, so we didn't care about the independence, and I don't remember my family being very proud of it. Mostly it's because no one really knew, how long the independence would last. At least, that's the feeling that I got.

\section{I: Were there any major changes made while you were in school?}

FS2: Well, in the beginning we were studying by Russian (Soviet) books, but later on Estonians started to publish their own books, which were awful. First of all these were translated from Estonian and the translation was often really bad, second it was hard to match the level of Estonian schools and Russian ones, because we always had different programs. All of us disliked new schoolbooks and mostly teachers continued to teach us by Russian ones, especially that concerns sciences (biology, chemistry, physics). When I was almost graduating, schools were slowly shifting to Estonian language; they launched experimental Estonian classes, who consisted of Russian kids starting to study in Estonian at once.

\section{I: Did the subject of "integration" come up often? How did people feel about it?}

FS2: I wouldn't say that in school much attention was paid to integration issues. It was always clear for us that we have to learn Estonian in order to succeed, but since all of our teachers were 
"old-school Soviet" people, they themselves often disliked the fact of living in independent country

\section{I: What do you remember about the curriculum at your high school (secondary school)? Were there any subjects that you felt were stressed more than others and why you think it was that way?}

FS2: Well $\mathrm{n}$ high school you stress those subjects on which you are planning to pass $\mathrm{s}$ state exam, so for me these were Estonian, English, Russian and Biology for others it was something else. Otherwise, I wouldn't recall any special emphasis on anything.

\section{I: How involved were you in the clubs and different activities at your school?}

FS2: I was quite active during the first 6 years of school and then kind of dropped out, because I didn't feel motivated. No one really cared about anything, so I didn't bother. I don't remember school as being a fun place. It was just something we had to do, a place to meet with friends.

\section{I: Can you remember any teachers in particular and why are they so memorable?}

FS2: I do remember a couple, yes. First there was our class teacher, she was teaching Biology and she was the almost person who genuinely cared about us. We loved her so much. A lot for what I have become I thank her.

Then there was a chemistry teacher - I remember her, because everyone was afraid of her. We were literally shivering before the class and when she called someone to answer to the front desk, she used to make a lot of jokes about students, sometimes even insulting a bit. She also gave private classes and was always biased to students who paid her money during those private lessons. We used to say, that if you want to have good grade for chemistry, you have to take some private lessons!

I also remember my English teacher. First of all I loved English. She was also a very professional and strong teacher, we all learned good English with her. She was also very small and used to wear enormously high heels every day. 


\section{I: How was the transition from secondary school to university? Do you feel like you were prepared enough? (Also, what faculty did you enter in university?)}

FS2: The school which I graduated from is a high ranked one in Tallinn (at least it used to be), so I had absolutely no problems to continue my education in the university. Even though school was entirely taught in Russian and university in Estonian - I encountered 0 problems (and I was not the best student in class, more an average one). I first majored in languages Estonian and English and got my bachelor in Arts of Humanities, later on I switched to Social Sciences and now History.

\section{I: What big events do you remember from when you were younger--maybe just at the community level--that involved communication between the different ethnicities of} Estonia?

FS2: I remember fights between Estonians and Russians in the streets. We would gather one team on one side of the street and they would have their team on the opposite side and then we would through stones or sticks on each other. I guess it was more of the game though, not hatred. We were kids and we realized that we are different, but we didn't put more thought into that.

I don't even remember any big events. I mean, I used to do a lot of sports and usually competed with Estonian kids on a local or sometimes national level too, but it was just about sports, nationality didn't matter

\section{I: Has the way that the ethnicities communicate changed?}

FS2: I guess yes, it changed, but to be honest it's hard to say in which direction. On the one hand I see younger generation being more aggressive to each other, on the other hand in some places it's not even a problem anymore.

\section{I: What do you think about the political representation in Estonia?}

FS2: I think people should think what is good for the country and not about the ethnicity of politicians. Estonian politics is disappointing me and I don't really want to go into that. Everyone is acting in his own interest 
Interview with Citizen C-received via e-mail Nov. 11, 2010

School: Tartu, public

Year Graduated: 2002

Ethnicity: Estonian

Interviewer : So I guess if you could just tell me about what you remember of your first day in school in Independent Estonia?

Citizen C: We were the first year students who went to first class in re-independent Estonia. I remember that even janitors were clapping their hands, it was so frightening for me and I didn't realize why are they doping this. Many years later I understood this, they were just so happy and greeted us in this way, because we were not Russians, there was no Russian class

\section{I: What is your reaction to debates about integration? (Such as Russian schools without current textbooks, adequate teacher training in Estonian language, cultural differences, etc.)}

$\mathrm{CC}: \mathrm{I}$ have to admit that I don't pay so much attention to these topics, because they are just debating and I don't see any results anyway. There are different ideas and thoughts that may be right, but also I have talked with Russians and they just say, they don't want to use word integration, it has a bad taste on. So in some way I can understand this.

\section{I: Do you see any major problems in the integration process? If so, what are they?}

$\mathrm{CC}$ : One problem that I have noticed is that at the beginning of integration process there were advertisements in Estonian language inviting Russians to come and study Estonian language. This was a huge problem.

\section{I: In your opinion is there enough interaction between Russian speaking Estonians and native Estonians?}

CC: I think there is interaction; humans are humans. Of course there are also a group of people who are staying out. Because of the fears or not feeling like this could happen. 
I: Do you think that there is still some tension between the ethnic groups? Is it it the same all over or different in different regions? How is it in your region?

$\mathrm{CC}$ : I think in my region there is not so much tension between ethnic groups. But in capital city there are a lot of cases, as I have heard.

I: How do you expect the strategic integration (especially in the schools) to change the society? (And if you have any), how soon do you expect these changes?

CC: Well, I really hope that one day we are not pointing out who is who, more of that everyone is equal and everyone enjoys living in Estonia. 
Interview with Former Student 3-Nov. 30, 2010, Tartu

School: Parnu, private

Year Graduated: 2006

Ethnicity: Estonian

Interviewer: What is your reaction to debates about integration? (Such as Russian schools without current textbooks, adequate teacher training in Estonian language, cultural differences, etc.)

Former Student 3: I tried to read some things about it - newspaper articles, argumentation on both sides. Maybe as an Estonian I am a little bit partial. Especially in view of the reports from UN or other organization criticizing the lack of rights for the Russian population. (Postimees) some people also read Eesti Ekspress but there probably isn't too big of a difference between the newspapers-like in UK or US. Except for specifically political newspapers.

For six years - it was optional, German or Russian, as a second foreign language. I knew that otherwise I would never learn it. I guess because of the history - it has a block against the Russian language. It doesn't come from family, but more from education and environment. But I really liked learning it, because I was quite good-Mom listens to Russian radio at home, but born and raised in Soviet era, but is Estonian. Says good things about the times, memories. Life was easier back then for some people.

\section{I: Do you see any major problems in the integration process? If so, what are they?}

FS3: The real problem is that we are trying to integrate something that can't be integrated. There is no way they will all become Estonian, and speak Estonian. WE cannot escape the problem. Time might help. It will take time. In order to forget, people are becoming more open. The country is becoming more multinational, as we get more foreigners from other countries, the Russians won't be so unique. Some things just stay in the mentality though. "Every nation in order to define itself is supposed to be opposed to something-small nation against a big power."

\section{I: In your opinion is there enough interaction between Russian speaking Estonians and native Estonians?}


FS3: I guess not, no. It is so much easier to stay among people who understand you fully and completely. STUDENT EXCHANGES — holiday exchanges. Our family was thinking about it but we never did, I would like to go to a Russian family to force me to learn the language more.

\section{I: Do you think that there is still some tension between the ethnic groups?}

FS3: Bronze soldier - a result not an effect. The tension outburst. It became more evident. When I discuss this issue with Russians, my Russian friends here in Estonia — we haven't had disagreements, but they are going to school here, and they speak Estonians. But I have never really heard about any antagonism from people. Russians from Russia see it as a bigger problem - I see it as a bigger problem between Estonia and Russia. The Russian media said that they broke the monument, which was not the case. Take this one piece of information, and use it against Estonia as propaganda. It hasn't made things worse, but became a reason to bring the issue up again. To blame other Estonians or Russians.

\section{I: Is it the same all over or different in different regions?}

FS3: I haven't had much contact with people from the East—so I can't make many generalizations about that, but in my mind, the people who live in Ida-Virumaa, their lifestyle is more Russian. Schools, churches, whatever, and so they don't need to use as much Estonian-so it is easier for Russians in Tartu to be more integrated.

\section{I: How do you expect the strategic integration (especially in the schools) to change the society? (And if you have any), how soon do you expect these changes?}

FS3: I guess it will change the rest of society in time. I guess it will change the society in a good way, make us more open and more tolerant. And change the viewpoint of "bad immigrants and good immigrants" -HUNTINGTON, almost the same thing. But it might just be a difference in culture - that it won't change, it will be good to have diversity. We can't all be the same. 
Interview with Former Student 4-Dec. 1, 2010, Tartu

School: Tallinn, public

Graduated: 2009

Ethnicity: Estonian

\section{Interviewer: First day?}

Former Student 4: We got our alphabet books and we had to learn a poem

\section{I: What is your reaction about debates of integration?}

FS4: After April I was a bit scared-I was in Tallinn, after the first night it was trashed. And the Internet commentaries were pretty violent. But otherwise, I'm pro-integration as it should be from both sides, but I also think that Russians should have to learn Estonian. I was just reading the Integration report, and some of them said that they aren't teaching Russian in Estonian schools as they were before-I think that it is ridiculous, since Estonian is the national language. I think it is a problem that there isn't enough information in the Russian community. They need more materials in Russian to explain things for naturalization and everything for them.

\section{I: In your opinion is there enough interaction between Russian speaking Estonians and native Estonians?}

FS4: In my experience, I know a couple of Russian Estonians, but they are really integrated. They go to Estonian universities, and have Estonian friends. But in general it isn't common for me. The part of Tallinn where I am from there isn't so much interaction. Mostly Estonians and upper-class live there.

\section{I: Do you think that there is still some tension between the ethnic groups? How is it in your region?}

FS4: I think we don't understand each other. There isn't enough communication. There are bad examples from both sides, I guess. I am scared of Russians when I go out in Tallinn. There isn't tension, I guess, but not enough understanding. Did I tell you I was in an integration project. We did this dancing marathon. So we talked to the Russian students in both Estonian and Russian, 
and it was really nice. I think it helps young people to acknowledge that there are two sides to the situation.

\section{I: Is it the same all over or different in different regions? How is it in your region?}

FS4: It is public knowledge that Ida-Virumaa is separate. It is historically so linked to Russia, and local governments there - most of the officials don't speak Estonian well enough to discuss the topics in Estonian - they get together before to discuss everything in Russian, and then they get together for the official meeting to vote in Estonian. It needs to happen so that the government can function, but its bending the rules for them too. Then again in Tallinn, it is because of the politicians. The mayor is really controversial - the Russians all vote for him. It's divided. You know that they will always vote for this same guy, Estonians are angry about this, I think. The Russian and Estonian presses are completely different too.

\section{I: Do you see any major problems in the integration process? If so, what are they?}

FS4: I don't know, I think it is because they don't get appropriate Estonian language skills - they need additional courses. 
Interview with Former Student 5-Dec. 1, 2010, Tartu

School: Hapsaalu — half-Swedish, Nuckö, public

Graduate: 2006

Ethnicity: Estonian

\section{I: What is your reaction about debates of integration?}

Former Student 5: Since Estonia gained independence again, 1991-1999, there was no proper integration program. During this last 10 years, I think it is too soon to make any final conclusions. I guess in some ways the integration program so far has kinda failed in some ways, but then again, it has only been 10 years. Media and public opinion definitely seems more negative than positive. They say that the integration program hasnt fulfilled the expectations, but they were kind of high as well. We had like 4-500,000 people with Russian background, to integrate then in 10 years is kinda impossible.

\section{I: In your opinion is there enough interaction between Russian speaking Estonians and native Estonians?}

FS5: In my high school I didnt have any contact with that, but i started to look more into integration at university. I guess that the people that go through integration they say that Estonian language is too hard to study, and there are not enough free language courses. They get reimbursement if they succeed, but otherwiese, not. The people say Estonian society is not very open minded, that the Estonians don't want Russians to be included. They feel very excluded. Even with the Estonian passport, they don't feel like they have a voice. One of the major issues

for me, in the current situation, is the people who dont have any passport at all. Approx. 8-9\% of total pop, in Estonia don't have any passport. They can go to Russia without a passport, and they can go to EU, but no where else. The integration foundation should focus on them-the process to get the passport is too difficult for them. Half of them enjoy the status, they don't really care.

\section{I: Do you think that there is still some tension between the ethnic groups? How is it in your region?}

FS5: There is definitely tension, but it isnt black and white. It is the same with Estonians as well, they have different opinions, it is a very delicate issue. 


\section{I: Is it the same all over or different in different regions? How is it in your region?}

FS5: Ida-Virumaa, main difference is language. There is always contact with Russians when I go home, either someone asks me something or I have to use Russian in a store. Eastern part of Estonia, is Estonia, even though it is populated by Russians.

I: Do you see any major problems in the integration process? If so, what are they?

FS5: No comment. 
Interview with Student 5-received via e-mail December 4, 2010:

Interviewer: Do you go to public or private school?

Student 5: I go to public school.

I: In which city do you go to school?

S5: I go to school in Rakvere (a small town, near my home)

I: What is your ethnicity?

S5: I'm Estonian

I: How old are you?

S5: I am 17 years old

I: Do you know about the Integration Program which is supposed to help Russian-speakers in Estonia and Estonians to work together more?

S5: I don't know anything about the Integration Program. I have not even heard of it.

I: What do you think about the debates about the benefits and failures of the Integration Program?

S5: I don't know nothing about the program, so I don't know its plusses and minuses.

I: Do you see the effects of Integration in your school?

S5: I don't see the effects of integration in my school.

\section{I: Do you see any problems from Integration? Any successes?}

S5: I think integration depends on people's personality. For example, a lot of people in Estonia don't communicate with Russians, because some Estonians hate them. 
I: Do you think there is enough interaction between Russian speakers in Estonia and Estonians? Do you think there is enough interaction between Russian speakers in your school and Estonians?

S5: I think there is enough of integration between Estonians and Russians. I don't like Russians, so I don't want to communicate with them. There is no Russians in my school, may be a few.

I: Do you feel tension between Russian speakers in Estonia and Estonians?

S5: I feel tension between Estonians and Russians all the time. A lot of people in Estonia don't accept them.

I: How do you expect Integration in schools to change Estonian society? How soon do you expect these changes?

S5: I don't expect integration in schools. I think that Russians and Estonians should be separately. 
Interview with Student 6-received via e-mail, Dec. 5, 2010

Interviewer: Do you go to public or private school?

Student 6: public school

I: In which city do you go to school?

S6: its not a city, its village near to Rakvere, Called Haljala.

\section{I: What is your ethnicity?}

S6: Estonian.

I: How old you are?

S6: 17

I: Do you know about the Integration Program which is supposed to help Russian-speakers in Estonia and Estonians to work together more?

S6: No, but you could talk about that :)

\section{I: Do you see any problems from Integration? Any successes?}

S6: Next question I can't answer because in my school everyone from Estonain families or speaks Estonian very well.

\section{I: Do you feel tension between Russian speakers in Estonia and Estonians?}

S6: No, I don't care where he or she from, his or her sight must be friendly for country where I am living and friendly for my family and friends and I am be a friendly with him/ her. 
Interview with Citizen D-Dec. 13, 2010, Tartu

Hometown: Tallinn

Age: 81

Ethnicity: Estonian

Interviewer: So I guess if you could just tell me about what you remember from your school days in Estonian SSR?

Citizen D: I remember the books. We were not given many options of which books we could study. They were all Russian. And not many of them. Maybe 3 for sociology. When the independence came, people were excited to share new books from the West.

I: What is your reaction to debates about integration? (Such as Russian schools without current text books, adequate teacher training in Estonian language, cultural differences, etc.)

CD: I think that sometimes it makes sense. It is a change, and most people don't like change. They may have lived here their whole lives, and now it is different.

I: Do you see any major problems in the integration process? If so, what are they?

CD: I can see how it would be harder in some places to learn Estonian. Like in Ida-Virumaa. There is not so much exposure. People in Tallinn even have trouble.

I: In your opinion is there enough interaction between Russian speaking Estonians and native Estonians?

$\mathrm{CD}$ : There is less than there should be for communities to work together.

I: Do you think that there is still some tension between the ethnic groups? Is it it the same all over or different in different regions? How is it in your region?

CD: It is hard to say. 
Interview with Former Student 6-received via e-mail Dec. 13, 2010

School: Tallinn, public

Year Graduated: 2008

Ethnicity: Estonian

Interviewer: What is your reaction about debates of integration?

Former Student 6: About the Integration program, I think it can be better, but there has been a great progress already.

\section{I: In your opinion is there enough interaction between Russian speaking Estonians and native Estonians?}

FS6: Between Russophones and Estonians, no.

\section{I: Do you feel tension between Russian speakers in Estonia and Estonians?}

FS6: There's certainly tension between Russians and Estonians (overall) ( I do like Russians :))

I: How do you expect Integration in schools to change Estonian society? How soon do you expect these changes?

FS6: I hope that integration in Estonia makes people more, how to say, comfortable with different nationalities and there won't be so many stereotypes. Though I don't think it will happen soon.

I think in school, it necessary - it broadens the mind and be very useful for our students. 


\section{APPENDIX D}

\section{Representation of Mutual Inter-Ethnic Attitudes}

Figure 22 Identification ${ }^{a}$ with ethnic groups by ethnic nationality, 2008

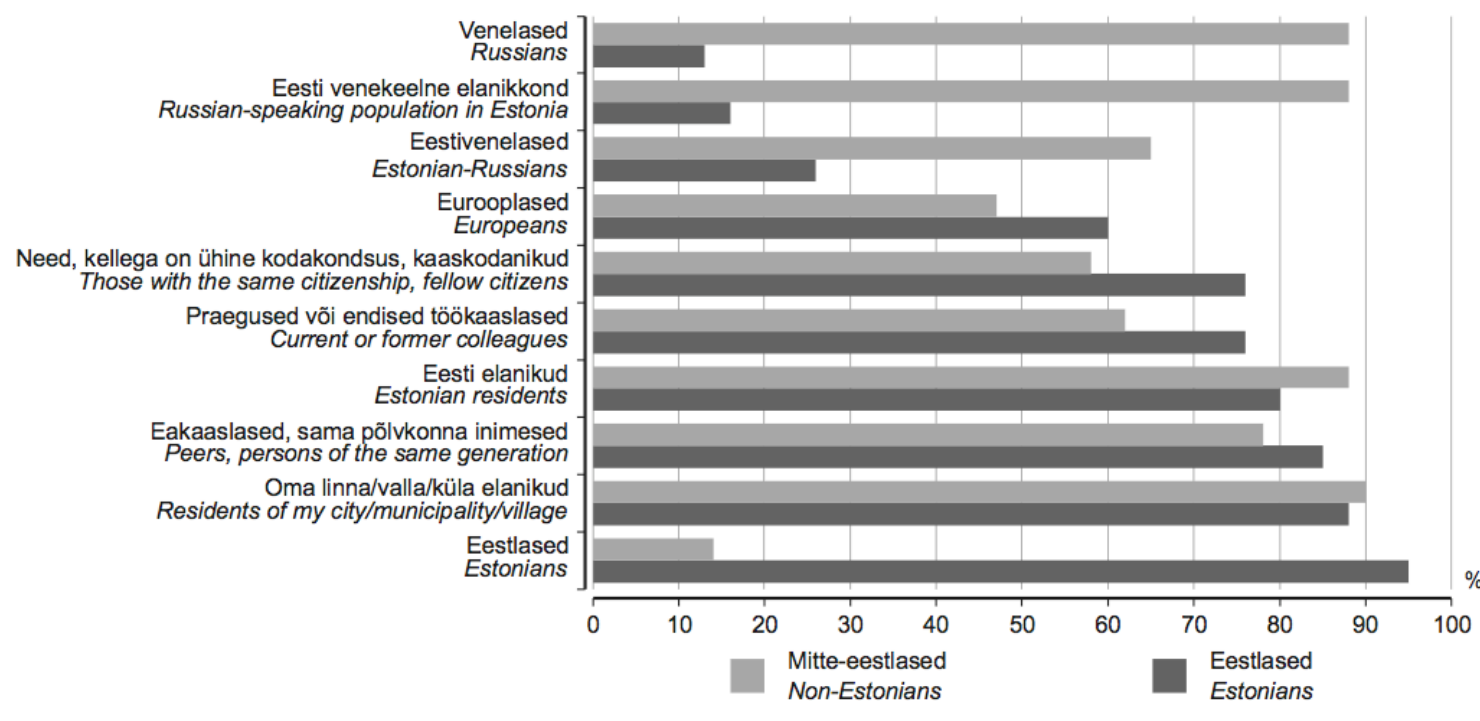

a Joonisel on koondatuna esitatud nende vastajate osatähtsus, kes pidasid end kindlasti ja pigem kindlasti nendesse rühmadesse kuuluvaks.

a The Figure summarises the percentages of respondents who said that they 'certainly' or 'rather certainly' identified themselves with the respective groups.

This comes from Siim Krusell, "Data and General Characterization of Immigrant Population," Immigrant Population (2009): 25. 


\section{APPENDIX E}

INTERVIEW, TALLINN CASE STUDY, MAY 31, 2010-10AM-11AM

Director of school invited 2 teachers, one English teacher (to help translate) and one Art teacher

for perspective, and 2 students in the $11^{\text {th }}$ form. Given a general history of the school and its background. Most of the interview was conducted through the translation of the English teacher.

\section{Interviewer: So what do you think are the main aims of your school in regards to the education reforms?}

Director C: We must teach good Estonian. The teachers especially need to be trained to teach Estonian.

\section{I: How have you been trying to achieve these goals?}

D: Through projects with other schools. Estonian schools. Sometimes it has been a problem that the other schools do not focus on math like we do. When Estonian students come here they did not talk too much. Maybe they didn't understand.

Student 3: I went on an exchange. The students at the Estonian school didn't speak much to me.

Teacher 2: Maybe there were just differences in culture.

D: We also have taken trips with the students. We have been to Brussels to see the seat of the European Union and to Saint Petersburg.

Teacher 3: Our graduates know that they need Estonian.

T2: A law was just passed that requires more subjects to be taught in Estonian. I think in the gymnasium[secondary-sic] level the subjects are literature, music, IT, social sciences, geography, and history. 
D: Unfortunately, we do not have a teacher capable of teaching History in Estonian yet. The demand is high for these kinds of bilingual teachers. But we have Physical Education in Estonian.

\section{I: Can you break down for me how often the students are trained in Estonian language right now?}

D: In the first form at our school the students will have 2 lessons of Estonian a week. In the second form it is increased to 3 times a week. In the $3^{\text {rd }}$ form they will get 4 lessons a week, and

that stays the same all through the $12^{\text {th }}$ form. Compulsory exams for Estonian language are given by the state. The ninth form should pass a B1 and in gynasium they should have a B2 level. You must have $60 \%$ to pass, and everyone in our school achieved at least $70 \%$. Even though our school primarily focuses on math, we still have very high scores in Estonian language.

\section{I: What is one of the contributing factors to this success do you think?}

D: Parental motivation is very important.

\section{I: (Directed to students) What activities outside of school do you participate in?}

Student 4: I play basketball. And I have gone to summer camps, sometimes in Estonian language. A lot of my teammates are Estonian. Tallinn is 50\% Russian and 50\% Estonian speakers. It is normal to have Estonian friends.

T3: A lot of the younger students seem to be more understanding of differences. It doesn't seem to matter much what language - they just like to play with their friends.

\section{I: A lot of the academic research on bilingual education recognizes that the students have more identity problems—how would you say you identify yourselves?}

T2: Definitely Russian.

S4: Russian first, then European maybe? I connect more with Russian culture. I speak Russian language at home. 
T3: This is somehow funny to me. I can hear how the students say they identify themselves, but really...when I visit my relatives in Russia, in Moscow, I feel Estonian.

\section{I: All of the educational reform that you have mentioned, how has it affected the teachers?}

D: The system is not so perfect. Teachers need to pass B2 who didn't study in Estonia. They can lose their jobs if they don't. This is a real problem for our teachers who are $50+$.

T2: The beginning was very hard after the collapse of the Soviet Union. The curriculum completely changed for us, and this was a big problem at the time. I used to teach in Rakvere at this time, and the quality of Estonian language education for Russian speakers was very poor. We couldn't find a teacher. The system needed more work.

D: A lot of attention was paid to students' books. Then after a while the situation improved.

\section{I: Can you tell me anything more about your school specifically?}

D: We do profound study for math. Also physics and chemistry. The extra hours for these subjects are not taken from the compulsory curriculum. Also, last year we celebrated 221 years. We have a folk dance group, and we go to some international competitions. We have two volleyball teams, too. A lot of activities for the students outside of the school—we are a very good organizer of extracurricular events. 


\section{APPENDIX F}

INTERVIEW, NARVA CASE STUDY, School B-MAY 28, 2010, 1PM

Researcher requested an interview with the director of School B in Narva. Director of school invited one English teacher to comment and help translate.

\section{I: Can you tell me more about your school? How has it been dealing with integration reform and government policy changes in the past few years?}

Director B: The students are finding it hard. They have language classes nearly every day. The language immersion at our school is 5 years. There is one form in each class. Five parallels, all the subjects are taught in Estonian. The language immersion teaches in Estonian and they communicate between classes in Estonian, too. It was school initiated. The parents choose to put their children in this class. It's not easy. Native speakers are hard to find and funding is difficult. There is no special funding for these classes, and they cost more money. The methodological training, however, is free. But there is a distinct advantage felt among the immersion students. The atmosphere is friendly and language is not a barrier for them. These pupils can continue in Estonian high school. The Russian-speaking pupils must have an upper intermediate level of Estonian, too.

\section{I: What do you think is a problem facing the educational system?}

B: In this region, language immersion works, but there is still a lot of support for Russian classes as well. At least, support for the parent's right to choose. As far as inside the schools, we only have native speakers teaching Estonian. The thinking is different, too, and this can be a barrier. We certainly could use more finances.

Teacher 1: Teachers need more material. Copies, technological things, books. It is stressful sometimes. To make the environment more comfortable, we need more money.

B: We have two teachers in the immersion classrooms as opposed to one in the regular classroom. This happens for 9 years.

\section{I: What are some extracurricular activities that the students are involved in regularly?}

B: The town is very active around the school. There is a school theatre, and a festival - they do plays every year. There are music performances, concerts, sports, etc. The school and the students have gotten many awards.

\section{I: How did you self-initiate the language immersion program?}

B: The center in Tallinn has been supporting the language immersion program with the advice they have given. They are very open to helping these programs. The Ministry of Education has given support as well as monitored the progress. We are not struggling for students who want to 
be involved. The decrease of students in the general population has not had any effect so far. In fact, this program has helped us keep a healthy competition. 


\section{APPENDIX G}

INTERVIEW, TARTU CASE STUDY-MAY 7, 2010, 9AM-12PM

Met with Director of School A

Offered Statistics (Oppeatutuse...) and explanations of the categories in English, general history of School A.

Two language immersion students came to help with translation and contribute to the interview.

Interviewer: Why do you offer language immersion?

Director: The opportunities that it affords students. Living in Estonia, they need to speak the national language for employment, study, etc.

\section{I: As far as language of instruction goes, how many classes are taught in Russian and how many are taught in Estonian?}

D: Half of the classes are taught in Estonian and half are in Russian.

Student 1: In the $6^{\text {th }}$ form all subjects are taught in Estonian. We are part of a "special project" with the government. It is very hard and unusual, but interesting. Of course there are certain subjects that are not taught in Estonian, like biology or chemistry or physics. But not all of those are taught to the $6^{\text {th }}$ form. And most teachers are bilingual.

\section{I: (Directed to the students) What are your plans for the future, where would you like to study or go to university?}

Student 2: Well really we have all possibilities. Personally I do not want to go to Russia, the degree doesn't seem useful and it is very expensive.

S1: I think I would like to go to University of Tartu. Or in Parnu they have a tourism school, which I think is what I want to do. I also have relatives in Vladivostok(Russia), so maybe there. 
S2: I really think it is better to study in English.

S1: It would be nice to study abroad. I think that would be a great opportunity.

\section{I:(Directed to the Director) Which teachers have been here the longest, have the most history with this school? And have there been any problems transitioning to this new program?}

D: I think I have been here the longest. 26 years. I used to teach Estonian language, so there never was a problem for me. Another teacher has been here 35 years - the Physics teacher, and he hasn't been affected by the language immersion program.

\section{I: What do you see as some of the problems facing the educational system?}

D: Well, for years the student numbers have been decreasing across Estonia. Our numbers are growing again. I think it is because we are offering our students more opportunities. Recently, Russian language is becoming more popular. We have our big neighbor, and there are business relationships and jobs that come from this. In the 1990's, people were not so receptive. It was very emotional, and people distanced themselves from Russia and Russian language. Now they have calmed down. Another thing is that the Russian population in Tartu is only $18 \%$.

\section{I: Do you see language as a problem for some of your teachers?}

D: All of the bilingual teachers, the ones in the immersion program have no problems. The older ones normally only teach classes in Russian, so that is not a big problem. One thing that we have noticed here and many places is the imbalance between men and women teachers. We only have 6 male teachers.

\section{I: What kind of extracurricular activities do you have? What kinds of programs are offered to students through the school?}

S2: There is a driving school, and the gym can be rented or reserved for teams. There is a football club, national dance club, sometimes we get a bunch of people together and play volleyball in the gym. There are choirs that sing in all languages. We really have a lot to do. 
D: We also have projects with other towns and schools. Sometimes we have student exchanges at Estonian language schools. Or video conferences. We get to communicate both ways. There are contests held between schools too. Some for singing or sports. One time there was a scavenger hunt. And a film contest.

\section{I: It sounds very competitive! (Directed at the students) Do you feel about the competition?}

(Students shake their heads.)

D: I think the teachers feel the competition more than the students. They feel pressure sometimes to be better than the other schools. Perhaps it influences them more. But the students will feel the competition later in life.

\section{I: Is the community very involved?}

D: We have a very active community. Our school is 45 years old this week and we have been celebrating a lot. We took a walk from the old building that the housed the school to here, and then had a big party.

\section{I: (Directed to the students) Do you get to use your language skills at home? Do your parents speak much Estonian?}

S2: I have a brother who is also in the program. But mostly we speak Russian at home. My mom can speak a couple of words and phrases. But my dad doesn't need to speak Estonian because he mainly works in Moscow.

S1: I live in a village outside of Tartu. When I was growing up I mainly spoke Estonian with my friends in the village, but we always spoke Russian at home. I think because of where I grew up, I started speaking more Estonian than a lot of the other students in our program.

*Students took Interviewer on tour of facilities, to sit in on a math class, to lunch, and to school presentation about art and culture-Minister of Culture gave talk (mostly in Estonian) about the implications of converting to the Euro in 2011. 